\title{
Greenland Ice Sheet seasonal and spatial mass variability from model simulations and GRACE (2003-2012)
}

\author{
Patrick M. Alexander ${ }^{1,2,3}$, Marco Tedesco ${ }^{2,1,4}$, Nicole-Jeanne Schlegel ${ }^{5,6}$, Scott B. Luthcke ${ }^{7}$, Xavier Fettweis ${ }^{8}$, and \\ Eric Larour ${ }^{6}$ \\ ${ }^{1}$ Graduate Center of the City University of New York, 365 5th Ave., New York, NY 10016, USA \\ ${ }^{2}$ City College of New York, City University of New York, 160 Convent Ave., New York, NY 10031, USA \\ ${ }^{3}$ NASA Goddard Institute for Space Studies, 2880 Broadway, New York, NY 10025, USA \\ ${ }^{4}$ Lamont Doherty Earth Observatory, Columbia University, 61 Route 9W, Palisades, NY 10964, USA \\ ${ }^{5}$ Joint Institute for Regional Earth System Science and Engineering, University of California, Los Angeles, CA 90095, USA \\ ${ }^{6}$ Jet Propulsion Laboratory, California Institute of Technology, 4800 Oak Grove Drive MS 300-227, Pasadena, \\ CA 91109, USA \\ ${ }^{7}$ Planetary Geodynamics Laboratory, NASA Goddard Space Flight Center, Greenbelt, MD 20771, USA \\ ${ }^{8}$ Laboratory of Climatology, Department of Geography, University of Liège, no. 2 Allé du 6 Aout, 4000, Liège, Belgium
}

Correspondence to: P. M. Alexander (patrick.m.alexander@ nasa.gov)

Received: 19 October 2015 - Published in The Cryosphere Discuss.: 19 November 2015

Revised: 9 April 2016 - Accepted: 23 April 2016 - Published: 20 June 2016

\begin{abstract}
Improving the ability of regional climate models (RCMs) and ice sheet models (ISMs) to simulate spatiotemporal variations in the mass of the Greenland Ice Sheet (GrIS) is crucial for prediction of future sea level rise. While several studies have examined recent trends in GrIS mass loss, studies focusing on mass variations at sub-annual and sub-basin-wide scales are still lacking. At these scales, processes responsible for mass change are less well understood and modeled, and could potentially play an important role in future GrIS mass change. Here, we examine spatiotemporal variations in mass over the GrIS derived from the Gravity Recovery and Climate Experiment (GRACE) satellites for the January 2003-December 2012 period using a "mascon" approach, with a nominal spatial resolution of $100 \mathrm{~km}$, and a temporal resolution of 10 days. We compare GRACE-estimated mass variations against those simulated by the Modèle Atmosphérique Régionale (MAR) RCM and the Ice Sheet System Model (ISSM). In order to properly compare spatial and temporal variations in GrIS mass from GRACE with model outputs, we find it necessary to spatially and temporally filter model results to reproduce leakage of mass inherent in the GRACE solution. Both modeled and satellite-derived results point to a decline (of $-178.9 \pm 4.4$ and $-239.4 \pm 7.7 \mathrm{Gt} \mathrm{yr}^{-1}$ respectively) in GrIS mass over the
\end{abstract}

period examined, but the models appear to underestimate the rate of mass loss, especially in areas below $2000 \mathrm{~m}$ in elevation, where the majority of recent GrIS mass loss is occurring. On an ice-sheet-wide scale, the timing of the modeled seasonal cycle of cumulative mass (driven by summer mass loss) agrees with the GRACE-derived seasonal cycle, within limits of uncertainty from the GRACE solution. However, on sub-ice-sheet-wide scales, some areas exhibit significant differences in the timing of peaks in the annual cycle of mass change. At these scales, model biases, or processes not accounted for by models related to ice dynamics or hydrology, may lead to the observed differences. This highlights the need for further evaluation of modeled processes at regional and seasonal scales, and further study of ice sheet processes not accounted for, such as the role of subglacial hydrology in variations in glacial flow.

\section{Introduction}

The Earth's ice sheets represent substantial reservoirs of water stored in the form of ice, which contribute to fluctuations in global sea level. The Greenland Ice Sheet (GrIS) in particular is estimated to have lost mass at an average rate of 
$-142 \pm 49 \mathrm{Gt} \mathrm{yr}^{-1}$ between 1992 and 2011 (Shepherd et al., 2012). Roughly $50 \%$ of recent GrIS mass loss is associated with surface mass loss (Rignot et al., 2011; van den Broeke et al., 2009), characterized by multiple records in GrIS melt extent and duration over the past decade (Tedesco et al., 2008, 2011, 2013a; Nghiem et al., 2012), which has led to increased meltwater runoff that exceeds small increases in ice-sheetwide precipitation (van den Broeke et al., 2009; Ettema et al., 2009; Fettweis et al., 2013a). The other portion of GrIS mass loss is associated with an acceleration of outlet glaciers (Rignot et al., 2011). The speed-up of glaciers has been attributed to warming oceans (Rignot et al., 2012) and lubrication of the GrIS bed from meltwater generated at the surface, and channeled from the surface to the bed by vertical conduits, allowing glaciers to slide more easily (Zwally et al., 2002). This second factor has been shown to be more complex than initially thought, resulting in speed-ups or slow-downs that depend on the volume of meltwater reaching the bed and the time of year (e.g., Sundal et al., 2011).

Previous studies have generally focused on decadal trends in GrIS mass and the ability of models to capture these trends (e.g., Shepherd et al., 2012; Rignot et al., 2011), but seasonal variations in mass, and spatial variations at sub-basin-wide scales have not been explored extensively. At smaller temporal and spatial scales, poorly understood processes may play a particularly important role in mass variability. For example, numerous studies have identified seasonal variations in glacial flow (Bartholomew et al., 2010; Howat et al., 2010; Joughin et al., 2008, 2014; Moon et al., 2014), and local variations in flow associated with lake drainage events or summer melting (Das et al., 2008; Tedesco et al., 2013b; Hoffman et al., 2011). Ice sheet hydrology can also contribute to local variations in mass. For example, an observational study by Rennermalm et al. (2013) suggests that within one catchment along the GrIS coast, up to $50 \%$ of runoff generated at the surface may have been stored within the ice sheet over multiple seasons. Water can also be stored at or near the surface of the ice sheet, within supraglacial lakes, or within firn aquifers, which were recently discovered to persist during winter over large areas of the southwest and southeast GrIS margins (Forster et al., 2013; Koenig et al., 2014). While the amount of water stored within supraglacial lakes is likely small relative to the overall rate of GrIS mass change (Smith et al., 2015), the amount of water stored within the firn aquifers or englacially is currently unknown.

The overall GrIS mass balance (MB), the rate of ice sheet mass change, is generally considered to consist of two components, the surface mass balance (SMB, i.e., the balance between accumulation and ablation at the ice sheet surface), and ice discharge $(D)$, such that $\mathrm{MB}=\mathrm{SMB}-D$. Simulations of SMB at high spatial and temporal resolutions (e.g., daily temporal resolution and $<25 \mathrm{~km}$ spatial resolution) are conducted by regional climate models (RCMs; e.g., Fettweis et al., 2013a; Ettema et al., 2009), and D can be simulated by ice sheet models (ISMs) (e.g., Larour et al., 2012; Qui- quet et al., 2012; Robinson et al., 2011; Huybrechts et al., 2011), which simulate glacial flow subject to SMB forcing. At seasonal and sub-basin-wide scales other processes become more important, so that the full mass balance is expressed as follows (after Cuffey and Paterson, 2011):

$\mathrm{MB}=\mathrm{SMB}+\mathrm{EMB}+\mathrm{BMB}+\mathrm{DMB}$,

where EMB is the englacial mass balance, BMB is the basal mass balance, and DMB is the mass balance associated with dynamic flow. Most processes related to EMB or BMB, as well as variations in DMB associated with ice-ocean interactions and meltwater lubrication, are not accounted for by either RCMs or ISMs. In a warmer climate, more meltwater production and runoff is expected (Fettweis et al., 2013b), suggesting that processes not accounted for will play an increasingly important role in future GrIS mass balance (Chu, 2014), and should be included in model projections of mass change.

Cognizant of the potential role of such processes in GrIS $\mathrm{MB}$, and the need for evaluation of the combined results of ISMs and RCMs, we conducted a comparison between satellite-derived mass changes from the Gravity Recovery and Climate Experiment (GRACE; Luthcke et al., 2013), modeled DMB from the Ice Sheet System Model (ISSM; Larour et al., 2012), and SMB from the Modèle Atmosphérique Régionale (MAR; e.g., Fettweis et al., 2013a) RCM for the period January 2003 through December 2012. The GRACE solution of Luthcke et al. (2013) (hereafter referred to as GRACE-LM) is provided at a high spatial and temporal resolution compared to other GRACE solutions ( $\sim 100 \mathrm{~km}$ and 10 days respectively). We aggregate model results to the GRACE-LM grid and spatially and temporally filter the aggregated outputs in order to match inherent spatial and temporal attenuation of the GRACE-LM product (as discussed by Luthcke et al., 2013; Sabaka et al., 2010). After filtering model outputs, we compared spatial patterns of simulated and satellite-derived mean annual mass balance, the mean annual cycle of mass change, and the spatial distribution of the timing of the seasonal cycle. This analysis has two purposes: (1) to evaluate seasonal and spatial variations in mass from the combined results of an RCM and ISM applied over the GrIS, and (2) to reveal and analyze any discrepancy between GRACE-derived and modeled mass changes, while accounting for uncertainties associated with the GRACE-LM solution.

\section{Data and methods}

\subsection{GRACE data}

We used the iterated global GRACE solution of Luthcke et al. (2013), which utilizes a mass concentration ("mascon") approach to derive spatially and temporally distributed changes in the mass of land ice, at a 1 arc degree $(\sim 100 \mathrm{~km})$ 
spatial resolution and 10-day temporal resolution. The solution is available for the period January 2003 through June 2013, but we focus on the January 2003 through December 2012 period to avoid including an incomplete year in our analysis. GRACE-LM mass change estimates are provided for $\sim 100 \times 100 \mathrm{~km}^{2}$ mascon regions, on what is essentially an equal area grid (shown in Fig. 1a). All GRACE solutions are ultimately derived from k-band range and range rate (KBRR) data for two co-orbiting satellites roughly $220 \mathrm{~km}$ apart (Tapley et al., 2004). The Luthcke et al. (2013) solution, used in this study, differs from other solutions in its approach: models of satellite motion are used to compute KBRR from forward-modeled mass changes, and through iteration, the residuals between the computed and observed KBRR are minimized. This contrasts with the spherical harmonic approach (e.g., Velicogna and Wahr, 2006) in which a set of Stokes coefficients or spherical harmonic fields provided by GRACE processing centers are spatially filtered and used to estimate spatial and temporal variations in mass. The mascon approach of Luthcke et al. (2013) attempts to minimize the loss of signal associated with processing GRACE data, and detailed error estimates, accounting for various steps in processing, are provided. The Luthcke et al. (2013) solution agrees within error estimates with other estimates for GrIS mass change derived from GRACE. As described by Luthcke et al. (2013), forward modeling is used during the processing of GRACE data to isolate the signal associated with land-ice changes. In particular, the static gravity field, orbital parameters, ocean and earth tides, terrestrial water storage, variations in mass associated with atmospheric and ocean circulation, and glacial isostatic adjustment are simulated by various models, and these simulated changes are used to correct GRACE-estimated mass change. The errors associated with each of these simulations are included in calculations of error for each GRACE-LM mascon. The GRACE-LM mascons are distributed at a resolution that is higher than the fundamental spatial resolution of GRACE (Luthcke et al., 2006), so that there is "leakage" of mass into and out of each mascon. This results in a spatial "smoothing" effect such that the change in mass for the area represented by a mascon is distributed over a radius of roughly $600 \mathrm{~km}$ from the mascon center (Luthcke et al., 2013). As a result, model outputs need to be consistently spatially filtered to allow a fair comparison with the GRACE-LM data. The details of this process are described further in Sect. 2.4.

\subsection{The MAR RCM}

The MAR RCM (Gallée and Schayes, 1994; Gallée, 1997; Lefebre et al., 2003) is a coupled surface-atmosphere RCM that has been applied over the GrIS to simulate current and future changes in SMB (e.g., Fettweis et al., 2013a; Franco et al., 2013). The atmospheric portion of MAR is described by Gallée and Schayes (1994), while the land surface model is the Soil Ice Snow Vegetation Atmosphere Transfer scheme

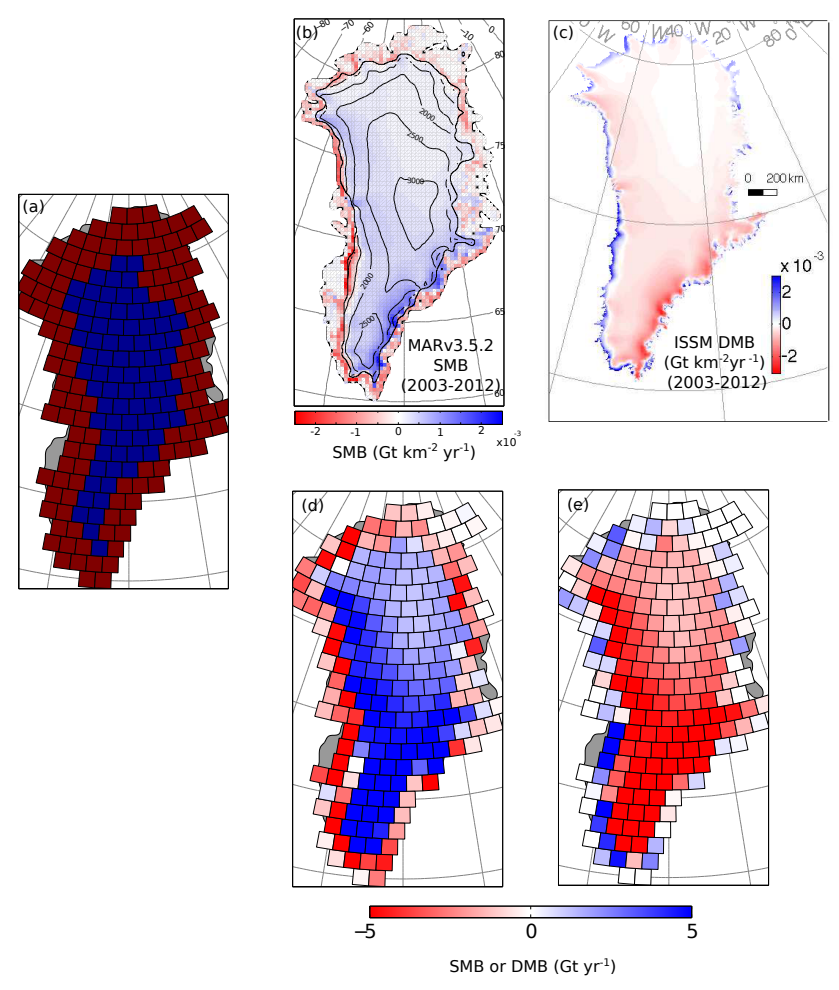

Figure 1. (a) Grid of mascons over the GrIS and constraint regions for the GRACE solution of Luthcke et al. (2013). Areas below $2000 \mathrm{~m}$ in elevation are red, while areas above $2000 \mathrm{~m}$ are blue. (b) MAR v3.5.2 average specific surface mass balance (SMB, $\mathrm{Gt} \mathrm{km}^{-2}$ $\mathrm{yr}^{-1}$ ) for January 2003-December 2012 on the MAR grid, for the GrIS and periphery (contours show elevation above sea level). (c) ISSM average specific dynamic mass balance (DMB, $\mathrm{Gt} \mathrm{km}^{-2}$ $\mathrm{yr}^{-1}$ ) for the same period on the ISSM mesh. SMB and DMB for the 2003-2012 period aggregated to the GRACE-LM grid (without filtering) are also shown for MAR v3.5.2 (d) and ISSM (e).

(SISVAT), containing the Crocus snow model (Brun et al., 1992). We use model outputs from two versions of the MAR model, MAR v2.0 (used by Fettweis et al., 2013a) for the period January 2003-December 2010, with the model domain and setup described by Fettweis (2007), and MAR v3.5.2, the latest version of MAR (used by Colgan et al., 2015), for the period January 2003-December 2012. For comparison with GRACE, we include MAR SMB for the entire island of Greenland, including the GrIS, peripherial ice-covered areas, and tundra areas, as Greenland mass changes related to snow and ice cover outside of the ice sheet boundaries are not removed in the GRACE solution. An overestimation of accumulation simulated by MAR v2.0 in the interior of the ice sheet (Vernon et al., 2013) was in part corrected in MAR v3.5.2 by slightly increasing the snowfall rate, producing more precipitation along the ice sheet margin and less inland. According to the recommendations of Alexander et al. (2014), MAR v3.5.2 features an updated bare ice albedo exponentially varying between 0.4 (dirty ice) 
and 0.575 (clean ice) as a function of the accumulated surface water height and slope. The bare ice albedo was fixed at 0.45 in MAR v2.0. Both MAR v3.5.2 and MAR v2.0 are forced every $6 \mathrm{~h}$ at the lateral boundaries by the ERA-Interim reanalysis (Dee et al., 2011) beginning in January 1979, and are run at a $25 \mathrm{~km}$ spatial resolution (as shown in Fig. 1b). This paper primarily focuses on results from MAR v3.5.2, which is used to force the ISSM ice sheet model. As will be discussed further in Sect. 2.4.2, the computationally intensive processing used in processing of GRACE-LM outputs had previously been applied to MAR v2.0 outputs, and we used these filtered MAR v2.0 outputs for the purpose of deriving a spatial filter to approximate spatial attenuation in the GRACE-LM solution.

\subsection{The ISSM model}

ISSM (Larour et al., 2012) is a thermomechanical ice sheet model that simulates ice flow in response to forcing from surface mass balance. The model solves equations for conservation of mass, momentum, and energy, in conjunction with constitutive equations for ice properties and boundary conditions. It has the capability of incorporating multiple approximations to the full Stokes (FS) ice flow equations in different regions. The model is implemented on a finite element mesh, which can be refined anisotropically to allow for a higher resolution in areas of high gradients in observed surface velocities. Inversion methods are used to derive constitutive properties such as ice rigidity and basal friction, by iteratively minimizing differences between radar-derived observed and modeled ice velocities (Morlighem et al., 2010; Larour et al., 2012).

In this study, ISSM has been run over the entire GrIS, following the model configuration of Schlegel et al. (2015), which uses a 2-D Shelfy-Stream Approximation to the FS equations (MacAyeal, 1989) in order to increase computational efficiency (as described by Larour et al., 2012). Aside from the inversion methods used to perform initialization of parameters for ice properties and basal friction, the model is forced only by SMB at the surface, subject to the boundary conditions described by Larour et al. (2012). Bedrock topography is defined using the radar and mass-conservationderived data set of Morlighem et al. (2015) (described in Morlighem et al., 2014). The GrIS simulation consists of an anisotropic mesh, which ranges in spatial resolution from 1 to $15 \mathrm{~km}$, consisting of 91490 elements. The MAR v3.5.2 mean SMB for the period January 1979-December 1988 is interpolated to a $5 \mathrm{~km}$ resolution using the method of Franco et al. (2012) to correct SMB with respect to subgrid topography as a function of the local vertical gradient of SMB, and is subsequently interpolated onto the ISSM mesh. Then it is used to spin up ISSM until the model reaches steady-state equilibrium; i.e., the change in GrIS mass over time is negligible (as described by Schlegel et al., 2013). Once the model reaches steady state (after 30000 years in this case), ISSM is forced monthly with SMB from the climate reconstruction of Box et al. (2013) and Box (2013) for the period January 1841-December 1979, adjusted so that the mean SMB for this period is equal to the MAR mean SMB of January 1979-December 1988. This ensures that ISSM responds to mean SMB from MAR, but incorporates anomalies from this mean beginning in 1841. MAR v3.5.2 SMB for the period January 1979-December 2013 is then used to force ISSM at a daily temporal resolution with a model time step of $12 \mathrm{~h}$. The cumulative mass change from MAR v3.5.2 and ISSM are then combined for comparison with GRACE. ISSM mean DMB for the period January 2003-December 2012 is shown in Fig. 1c.

\subsection{Methods of comparison}

In order to properly compare model results with the GRACELM solution, it was necessary to first spatially aggregate model data to the GRACE grid, to account for the different resolution of different products (Sect. 2.4.1). Second, in order to conduct a fair comparison with GRACE-LM at the spatial and temporal resolution of the GRACE-LM solution, model results must be spatially and temporally filtered to account for spatial and temporal attenuation of the GRACE signal, associated with the leakage of mass changes from each mascon into nearby mascons in space and time (Luthcke et al., 2013). The best means of filtering model data for comparison to GRACE-LM is to apply the equations used in GRACE-LM processing directly to the model data (Sect. 2.4.2). Because this process is computationally intensive, however, we approximated the effect of GRACELM processing using spatial and temporal Gaussian filters (Sect. 2.4.3). Although our approximation does not perfectly reproduce the effect of GRACE filtering in space and time (Sect. 2.4.5), we adopt a statistically conservative approach in our comparison between GRACE-LM and model outputs, to identify cases where differences are unlikely to be a result of filtering or errors in the GRACE-LM solution (discussed in Sect. 2.4.4).

\subsubsection{Spatial aggregation}

MAR and ISSM daily outputs for the period January 2003December 2012 were spatially aggregated into GRACE-LM mascons (Fig. 1d and e). In the case of ISSM data, ISSM dynamic thickness changes (ice thickness change associated only with dynamic motion of ice) on the anisotropic mesh were first interpolated onto a $10 \mathrm{~km}$ equal area grid, converted into mass changes using the density of ice $\left(917 \mathrm{~kg} \mathrm{~m}^{-3}\right)$, and then aggregated to the nearest GRACELM mascon to produce time series of DMB for each mascon. In the case of MAR data, MAR SMB outputs at a $25 \mathrm{~km}$ resolution were aggregated to the nearest mascon. The sum of mass change simulated by each model was then calculated for each mascon. Over the oceans, all mass changes 
predicted by MAR (likely associated with accumulation over sea ice) were set to zero, as such accumulation does not result in changes in mass due to the presence of isostatic adjustment of sea ice over the oceans.

\subsubsection{Spatial and temporal filtering using GRACE equations}

The GRACE-LM solution uses a Gauss-Newton (GN) procedure to adjust an equivalent height of water within each mascon to produce perturbations in the GRACE spherical harmonic fields or Stokes coefficients. The partial derivatives of the Stokes coefficients with respect to the equivalent water height, and the partial derivatives of KBRR with respect to the Stokes coefficients are then used to determine the change in KBRR associated with a change in equivalent water height. The GN procedure iteratively adjusts equivalent water height within all mascons to minimize the residuals between computed KBRR and KBRR observations. The final GRACE-LM solution for a given mascon is not the "true" mascon state, but differs from it due to leakage between mascons and the presence of noise in the solution. The relationship between the true mascon state $h_{k}$ and the updated mascon state $\widetilde{h}_{k}$ is given by Eq. (8) of Luthcke et al. (2013), expressed as

$\widetilde{\boldsymbol{h}}_{k+1}=\mathbf{R} \boldsymbol{h}_{k}+\mathbf{K} \boldsymbol{e}$,

where $\boldsymbol{e}$ represents added noise, and $\mathbf{R}$ is referred to as the resolution operator, as it serves the function of smoothing the true mascon states $\boldsymbol{h}_{k}$ in space and time. $\mathbf{K}$ and $\mathbf{R}$ are in turn expressed by

$\mathbf{K}=\left(\mathbf{L}^{T} \mathbf{A}^{T} \mathbf{W A L}+\mu \mathbf{P}_{h h}\right)^{-1} \mathbf{L}^{T} \mathbf{A}^{T} \mathbf{W}$

$\mathbf{R}=\mathbf{K A} \mathbf{A}$,

where $\mathbf{L}$ represents the partial derivatives of the Stokes coefficients with respect to the mascon state, $\mathbf{A}$ represents the partial derivatives of the KBRR observations with respect to the Stokes coefficients, and $\mathbf{W}$ is a data weight matrix that accounts for orbital parameters and corrections for processes not related to ice sheet mass changes (e.g., isostatic adjustments, tides). $\mathbf{P}_{h h}$ is a regularization matrix, which constrains the solution so that differences in mass change between mascons closer together are minimized (Sabaka et al., 2010). Constraint regions for the GrIS are also defined (Fig. 1a) such that the constraint does not apply across the boundaries of the constraint region. Thus, for the GrIS, changes in mass above $2000 \mathrm{~m}$ in elevation, where the MB is generally positive, can occur independently of changes in mass below $2000 \mathrm{~m}$ in the GRACE-LM solution (Luthcke et al., 2013).

In order to spatially filter MAR data to match GRACELM, we applied the resolution matrix to the aggregated MAR v2.0 data, using Eq. (2), taking the aggregated MAR v2.0 on GRACE-LM mascons as the true mascon states $\boldsymbol{h}_{k}$, and ignoring the added noise term $\boldsymbol{e}$. The resulting updated mascon states $\widetilde{\boldsymbol{h}}_{k+1}$ are MAR v2.0 data spatially and temporally filtered to match GRACE-LM. The effect of spatial smoothing on the MAR v2.0 aggregated outputs (Fig. 2a), along with the impact of different constraint regions above and below $2000 \mathrm{~m}$ in elevation, can be seen in Fig. 2b, which shows the mean January 2003-December 2010 MAR v2.0 outputs filtered using the resolution matrix. As expected, the spatial filtering decreases the magnitude of mass change for individual mascons by redistributing mass change across other surrounding mascons.

Unfortunately, the methods discussed above (hereafter referred to as "GRACE-LM filtering") are computationally expensive and time-consuming to perform. We only applied GRACE-LM filtering to MAR v2.0 outputs as only these outputs were available when the GRACE-LM filtering procedure was applied. To filter MAR v3.5.2 and ISSM data, we employed an approximation to the GRACE-LM filtering procedure, which is described further below.

\subsubsection{A Gaussian approximation to GRACE-LM filtering}

As discussed by Luthcke et al. (2013), the leakage associated with individual GRACE-LM mascons is roughly equivalent to a spatial Gaussian filter with a radius of $300 \mathrm{~km}$, with the mascons within a $600 \mathrm{~km}$ radius accounting for almost $100 \%$ of the mass changes within a mascon. To allow for spatial filtering of MAR v3.5.2 and ISSM outputs, we developed an approximation to the GRACE-LM filtering using a Gaussian filter. The Gaussian function can be expressed as a function of distance from the center of the distribution $(x-\mu)$, where $x$ is the $x$-coordinate and $\mu$ is the mean of the distribution, and a standard deviation $(\sigma)$ as

$g(x)=\frac{1}{\sigma \sqrt{2 \pi}} e^{-\frac{1}{2}\left(\frac{x-\mu}{\sigma}\right)^{2}}$.

We used a Gaussian function to weight the data for all surrounding mascons $(j)$ as a function of radial distance from a central mascon $(i)$. In this case, $x-\mu$ is replaced by the distance from a central location to another mascon $\left(r_{i j}\right)$, and a discrete approximation to the Gaussian is used, as follows:

$g\left(r_{i j}\right)=e^{-\frac{1}{2}\left(\frac{r_{i j}}{\sigma_{j}}\right)^{2}}$
$w_{j}=\frac{g\left(r_{i j}\right)}{\sum_{j=1}^{n} g\left(r_{i j}\right)}$.

The weight, $w_{j}$, assigned to a given mascon, $j$, at a distance $r_{i j}$ from mascon $i$, is given by the value of the Gaussian function at the center of mascon $j$ divided by the sum of all Gaussian values surrounding mascon $i$. A different $\sigma_{i}$ value is chosen for each mascon, as will be explained further below.

We further modify Eq. (7) to account for the constraint regions discussed in the previous section, which for the GrIS, include areas above and below $2000 \mathrm{~m}$ in elevation (Luthcke 
et al., 2013). For a given mascon within a constraint region (mascon $i$ ), weights for mascons outside of the constraint region were multiplied by a leakage parameter, $\lambda_{i j}$, which represents the fraction of mass in mascon $j$ outside the constraint region that influences the mass change in mascon $i$. Accounting for these constraints, Eq. (7) becomes

$w_{j}=\frac{g\left(r_{i j}\right) \lambda_{i j}}{\sum_{j=1}^{n} g\left(r_{i j}\right) \lambda_{i j}}$,

where $\lambda_{i j}$ for mascon $i$ is set equal to 1 within the constraint region, and equal to a constant value between 0 and 1 for all mascons $j$ outside of the constraint region.

The weights for mascons $j$ surrounding a central mascon $i$ are then used to create a weighted average of mass change for mascon $i\left(\Delta m_{i, \text { new }}\right)$ as a function of the modeled changes for mascon $i\left(\Delta m_{i}\right)$ and mascons $j\left(\Delta m_{j}\right)$ :

$\Delta m_{i, \text { new }}=\Delta m_{i} w_{i}+\sum_{j=1}^{n} \Delta m_{j} w_{j}$.

Finally, we added a time component to the filtering procedure, as the regularization matrix $\left(\mathbf{P}_{h h}\right)$ discussed in Sect. 2.4.2 also includes a temporal component (Sabaka et al., 2010), and because GRACE-LM filtering alters both the amplitude and timing of the seasonal cycle of mass change (as discussed in Sect. 2.4.5). After applying the spatial filter described by Eqs. (6) and (8), time series of cumulative mass from MAR v2.0 were interpolated onto GRACE-LM time intervals. We then applied a temporal Gaussian filter to the cumulative mass time series for each mascon, using the temporal radius $\Delta t_{t 0 t k}$, where $t_{0}$ is a point in time along the time series, $t_{k}$ is a time before or after the time $t_{0}$, and $\Delta t_{t 0 t k}=\left|t_{k}-t_{0}\right|:$

$g\left(\Delta t_{t 0 t k}\right)=e^{-\frac{1}{2}\left(\frac{\Delta t_{t 0 t k}}{\sigma_{\text {time }}}\right)}$

$w_{t k}=\frac{g\left(\Delta t_{t 0 t k}\right)}{\sum_{k=m}^{n} g\left(\Delta t_{t 0 t k}\right)}$,

where $m$ is the first value in the time series being filtered and $n$ is the last value. The filtering was applied at each time $t_{0}$ to produce a time series of filtered cumulative mass change.

We applied the spatial and temporal filters discussed above to the aggregated unfiltered MAR v2.0 data, and compared the resulting cumulative mass time series from each mascon to the GRACE-LM-filtered MAR v2.0 time series. Two filtering procedures were employed, one in which only spatial filtering was performed, and another in which both spatial and temporal filtering were performed to determine the impact of temporal filtering. We iteratively adjusted the values of $\sigma_{i}$, $\sigma_{\text {time }}$ (in the case of temporal filtering), and $\lambda_{i j}$, for each mascon $i$. Values of $\sigma_{i}$ were varied at $10 \mathrm{~km}$ increments over a range of 1 to $600 \mathrm{~km}$, while values of $\sigma_{\text {time }}$ ranged between 1 and 91 days at increments of 5 days, and $\lambda_{i j}$ ranged between 0 and 1 at increments of 0.01 . We tried all combinations of
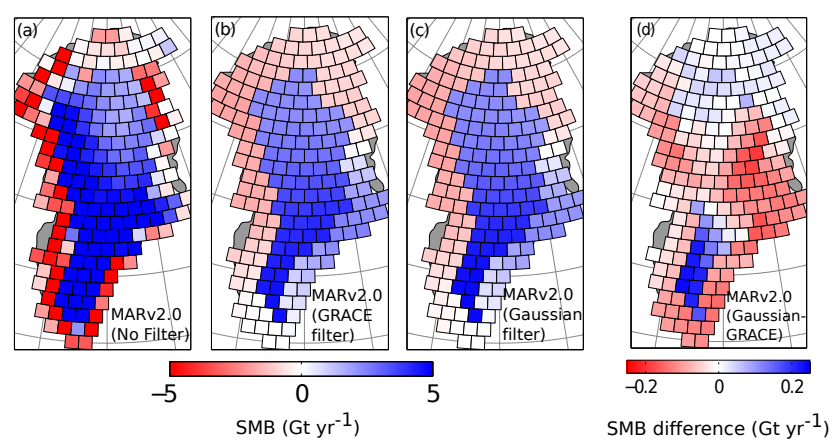

Figure 2. Average MAR v2.0 SMB $\left(\mathrm{Gt} \mathrm{yr}^{-1}\right)$ for the period January 2003-December 2010: (a) averaged onto GRACE-LM mascons with no filtering, (b) filtered using the resolution operator from GRACE-LM processing, (c) filtered using a Gaussian approximation to GRACE-LM filtering in space and time. (d) The difference between (a) and (b). Note the difference in color scale for (d).

the three parameters over these ranges. The combination of parameters that yielded the minimum root mean squared error (RMSE) between the Gaussian-filtered and GRACE-LMfiltered cumulative mass time series was taken as the optimal set of parameters for a given mascon. We also tried applying the same values of $\sigma_{i}, \sigma_{\text {time }}$, and $\lambda_{i j}$ across all mascons $i$ over the specified range of each parameter, but it was found that by spatially varying the values of these parameters the errors were reduced. We also set $\lambda_{i j}$ equal to zero outside of the island of Greenland as defined by the GRACE-LM mascons, as this improved the agreement with the GRACELM-filtered results. We tried larger values of $\sigma_{i}$ beyond the indicated range at larger increments, but did not find a reduction in RMSE for values larger than $600 \mathrm{~km}$.

Average Gaussian-filtered MAR v2.0 SMB (with both spatial and temporal filtering applied) for the period 20032010 is shown in Fig. 2c. The Gaussian-filtered MAR v2.0 SMB is similar to GRACE-LM-filtered SMB. Differences between the GRACE-LM-filtered and Gaussian-filtered results (Fig. 2d) are an order of magnitude smaller than the average SMB values (ranging from -0.2 to 0.2 vs. -2 to $5 \mathrm{Gt}$ ), although in some regions where trends in SMB are small, the differences are a large percentage of the average SMB. Optimal values for $\sigma_{i}, \sigma_{\text {time }}$, and $\lambda_{i j}$ and the RMSE for the Gaussian vs. the GRACE-LM-filtered MAR v2.0 data are shown in Fig. 3. Further discussion of the impacts of filtering on model outputs is provided in Sect. 2.4.5.

\subsubsection{Application of Gaussian filters, seasonal cycle analysis, and trends}

Following the choice of the optimal Gaussian filter using MAR v2.0, we applied the same chosen filter to MAR v3.5.2 and ISSM data forced by MAR v3.5.2, aggregated to the GRACE-LM grid. MAR v3.5.2 exhibits a less negative SMB along the Greenland coast and GrIS margins and a less pos- 
itive SMB within the GrIS interior (Fig. S1 in the Supplement) compared with MAR v2.0 (as there is more coastal accumulation and less interior accumulation in MAR v3.5.2). These differences do not affect our ability to filter MAR v3.5.2 outputs, as the Gaussian filter does not depend on mass changes, but approximates the GRACE-LM resolution operator, which serves to redistribute mass changes subject to specified constraint regions. Spatial filtering of MAR v3.5.2 and ISSM was conducted first at a daily temporal resolution. Filtered cumulative mass time series for each mascon were then interpolated onto GRACE-LM time steps, and temporal filtering was performed. We then summed the time series of cumulative mass change from MAR v3.5.2 and ISSM, to generate time series of integrated MB.

We examined differences between the modeled and GRACE-LM seasonal cycles of cumulative mass change by first linearly interpolating filtered cumulative model and GRACE-LM time series onto daily time steps. This was necessary because the GRACE-LM time steps are not evenly spaced, and do not occur at the same point in time every year. We then subtracted the long-term linear trend for the entire time series (2003-2012) obtained from least-squares regression, to remove the impact of differences in trends on the timing of the seasonal cycle. After removing trends, the cumulative mass value for a given day of the year was averaged across all years in the 2003-2012 period, to yield an average annual cycle for all years. The maximum and minimum peaks were computed from this average annual cycle. This was performed for the GrIS-wide time series, as well as for individual mascons and GrIS subregions.

GRACE data from Luthcke et al. (2013) include estimates of the error associated with the time series of cumulative mass change for each mascon. When examining aggregated data, we summed the error for all mascons. The error for a given day for the GRACE-LM seasonal cycle was determined to be the total GRACE-LM error for the cumulative time series divided by $\sqrt{n}$, where $n$ was the number of years being averaged. Errors in the GRACE-LM time series can lead to errors in the timing of the seasonal cycle because random errors can cause a shift in the timing of a local maximum or minimum point. To account for these errors, we performed 10000 Monte Carlo simulations with the GRACELM seasonal data, assuming that the errors in the time series were normally distributed. For each of these simulations, a time series of randomly distributed noise with standard deviation equal to the error was added to the GRACE-LM time series at 10-day intervals beginning on 1 January (roughly corresponding to the temporal resolution of the GRACE-LM solution). The error was applied on 10-day intervals as the GRACE-LM error is defined for roughly this temporal resolution. For each simulation, we identified the local maximum and minimum peaks in the seasonal cycle, allowing us to generate a distribution of dates for maximum and minimum peaks. The temporal resolution of the GRACE-LM data set, and the addition of errors at 10-day intervals can also lead to

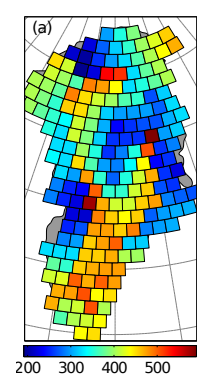

$\sigma_{i}(\mathrm{~km})$

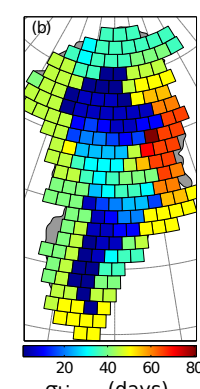

$\sigma_{\text {time }}$ (days)

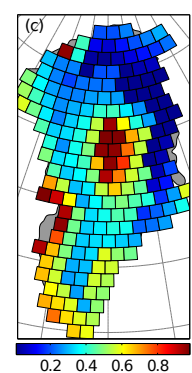

$\lambda \mathrm{ij}$ (unitless)

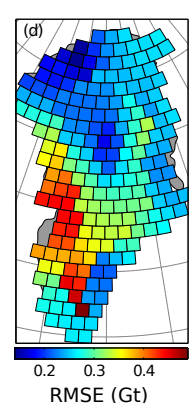

Figure 3. Optimal values of parameters used in spatial and temporal Gaussian filtering of MAR v3.5.2 and ISSM data: (a) the spatial Gaussian radius, (b) the temporal Gaussian radius, and (c) the leakage parameter. (d) RSME (Gt) for GRACE-LM-filtered vs. Gaussian-filtered MAR v2.0 (January 2003-December 2010).

errors of roughly \pm 10 days for the timing of any estimate. Given that the error could be as large as 10 days, we calculated our error on the timing of seasonal cycle peaks as the $95 \%$ confidence interval from the Monte Carlo simulations, \pm 10 days. If model peaks fell outside of this error range, the timing of the GRACE-LM and model peaks was deemed to differ.

We also compared modeled and GRACE-LM trends for the 2003-2012 period. To calculate the uncertainty in trends from GRACE-LM, we employed a similar procedure to estimate uncertainty in trends, conducting 10000 Monte Carlo simulations and obtaining a distribution of trends and uncertainty values (from the $95 \%$ confidence interval for calculated each trend). The error on the trend was calculated as the average of the 2.5 and $97.5 \%$ deviations from the trend added to the $97.5 \%$ (upper) bound on the distribution of uncertainty values. For all model estimates, uncertainty on trends is reported as the $95 \%$ confidence interval obtained during linear regression.

\subsubsection{Effect of filtering on seasonal variations in mass}

As we were interested in examining seasonal variations in mass, we examined the impact of GRACE-LM filtering vs. Gaussian filtering (spatial only and spatial + temporal) on the cumulative time series of GrIS-wide mass changes, in relation to the seasonal cycle of mass change from GRACELM. While it is not possible to compare GRACE-derived mass changes directly to MAR, given that GRACE also records the effects of changes in DMB, a comparison of detrended time series of cumulative mass can be performed, if it is assumed that seasonal variations in ice discharge are small relative to those of SMB. A qualitative comparison of detrended unfiltered and filtered MAR v2.0 and GRACELM cumulative mass time series for the GrIS over January 2003-December 2010 (Fig. 4) suggests that this is a reasonable first-order assumption for the entire GrIS. (As will be seen in Sect. 3.2, modeled ice-sheet-wide seasonal variability 


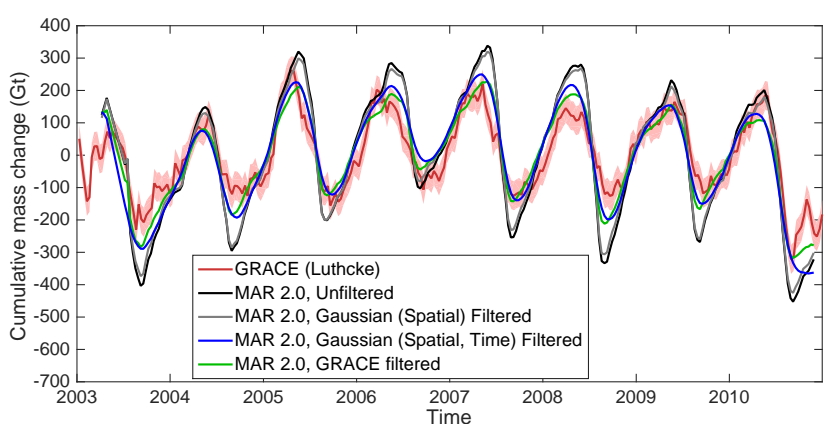

Figure 4. Detrended time series of cumulative GrIS-wide mass change, for GRACE-LM, MAR v2.0 (unfiltered), MAR v2.0 (GRACE-LM-filtered), and MAR v2.0 (Gaussian-filtered) for January 2003-December 2010. Time series are shown for Gaussianfiltered MAR v2.0 outputs subject to only spatial filtering (gray curve) and both spatial and temporal filtering (blue curve). The pink shading indicates the range of error for the GRACE-LM time series.

from ISSM is also less than $10 \%$ of variability from MAR.) Fluctuations in mass, coinciding with net loss of mass during summer months, and net gain of mass during winter months, are captured by both GRACE-LM and MAR v2.0. The average seasonal cycle of cumulative mass change in Fig. 5a indicates a larger amplitude of mass fluctuations for unfiltered and spatially Gaussian-filtered MAR v2.0 results (of 524 and $500 \mathrm{Gt}$ respectively) relative to GRACE-LM $(287 \pm 30 \mathrm{Gt})$, and a closer agreement between the amplitudes of GRACELM-filtered MAR v2.0 data (339 Gt) and GRACE-LM. On average, during periods of net ablation, GRACE-LM begins losing mass earlier (by 25 days), and starts gaining mass later (by 8 days) as compared with MAR v2.0 unfiltered data (Table 1). GRACE-LM filtering changes the timing of the start of mass loss such that the period of simulated mass loss begins 10 days sooner, extending the length of the mass loss period.

When both spatial and temporal Gaussian filtering are applied to the MAR v2.0 data, the amplitude of the seasonal cycle is reduced (to $351 \mathrm{Gt}$ ), resulting in a better agreement with GRACE-LM and with the GRACE-LM-filtered MAR v2.0 data (Fig. 5a). The timing of peaks in maximum and minimum mass are also changed, with the temporally Gaussian-filtered MAR v2.0 data exhibiting an extended period of mass loss (145 days) relative to that of the GRACE-LM-filtered MAR v2.0 data (123 days), resulting in the filtered seasonal cycle peaks occurring within 5 days of GRACE-LM peaks. In all cases, however, the timing of peak mass loss from MAR v2.0 falls within the $95 \%$ confidence bounds on maximum and minimum dates for GRACE-LM.

Adding temporal Gaussian filtering improves the agreement between the Gaussian-filtered MAR v2.0 time series and the GRACE-LM-filtered time series in terms of amplitude, and lengthens the period of net ablation (perhaps too much relative to the period for GRACE-LM-filtered data).
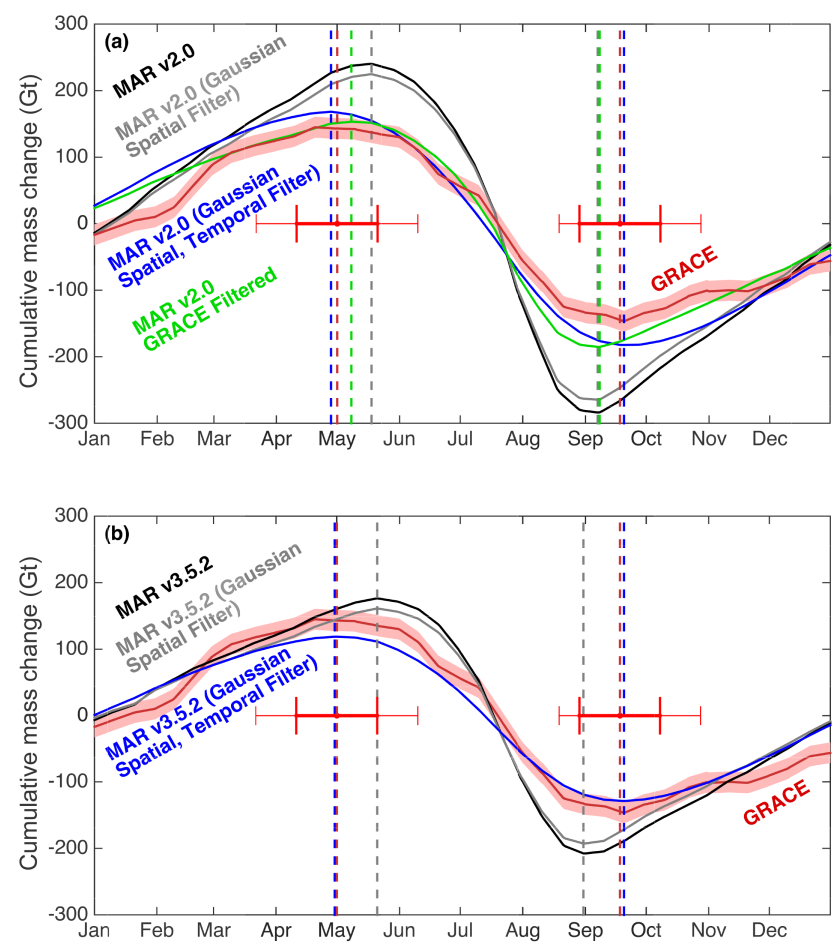

Figure 5. Average seasonal cycle of January 2003-December 2010 GrIS-wide detrended cumulative mass change (a) for GRACE-LM, unfiltered MAR v2.0 data, GRACE-LM-filtered MAR v2.0 data, and Gaussian-filtered MAR v2.0 data (with spatial filtering and spatial + temporal filtering). (b) The same as (a), for MAR v3.5.2 (for which GRACE-LM-filtered data are not available). Vertical dashed lines indicate the timing of peaks of maximum and minimum mass in the cycle. Red horizontal error bars indicate the error in the timing of the GRACE cycle. Bold error bars indicate $50 \%$ of the GRACELM distribution, and thin red lines indicate $95 \%$ of the distribution. The error bars have been extended for 10 days in either direction to account for errors associated with temporal resolution.

For both methods of Gaussian filtering, the timing of the peaks for filtered MAR v2.0 data falls within the $95 \%$ confidence bounds on the timing of the GRACE-LM seasonal cycle.

The comparison of GRACE and MAR time series and seasonal cycles in the case of MAR v3.5.2 (Figs. S2 and 5b respectively) is similar to that for MAR v2.0. MAR v3.5.2 features a seasonal cycle of smaller amplitude, likely as a result of snow falling more frequently along the coast, where it is more likely to be balanced by ablation during periods of net accumulation, and where it mitigates ablation during periods of net mass loss. The Gaussian filtering has a similar effect on the MAR v3.5.2 outputs, which are similar in timing to MAR v2.0 outputs (Table 1), by reducing the amplitude of seasonal variability and extending the length of the ablation season to be similar to that of GRACE-LM (Fig. 5b and Table 1). In our analysis of ISSM and MAR v3.5.2 outputs, we have chosen to focus on results obtained by applying both spatial and 
Table 1. Timing of maximum and minimum peaks in the seasonal cycle of GrIS-wide detrended cumulative mass change for GRACE-LM and MAR for the January 2003-December 2010 period. For GRACE-LM, the median value and bounds for the $95 \%$ confidence interval of the distribution after accounting for uncertainty in GRACE-LM are listed. The uncertainty bounds have been extended by 10 days to account for potential errors associated with temporal resolution.

\begin{tabular}{|c|c|c|c|c|c|c|c|}
\hline & GRACE & $\begin{array}{l}\text { MAR v2.0 } \\
\text { unfiltered }\end{array}$ & $\begin{array}{l}\text { MAR } \\
\text { v3.5.2 } \\
\text { unfiltered }\end{array}$ & $\begin{array}{l}\text { MAR v2.0 } \\
\text { GRACE- } \\
\text { filtered }\end{array}$ & $\begin{array}{l}\text { MAR v2.0 } \\
\text { Gaussian- } \\
\text { (spatially) } \\
\text { filtered }\end{array}$ & $\begin{array}{l}\text { MAR v2.0 } \\
\text { Gaussian- } \\
\text { (space, } \\
\text { time) } \\
\text { filtered }\end{array}$ & $\begin{array}{l}\text { MAR } \\
\text { v3.5.2 } \\
\text { Gaussian- } \\
\text { (space, } \\
\text { time) } \\
\text { filtered }\end{array}$ \\
\hline $\begin{array}{l}\text { Maximum } \\
\text { ( } 2.5 \% \text { bound })\end{array}$ & $22 \mathrm{Mar}$ & & & & & & \\
\hline Maximum & 1 May & 18 May & 21 May & 8 May & 18 May & $28 \mathrm{Apr}$ & $30 \mathrm{Apr}$ \\
\hline $\begin{array}{l}\text { Maximum } \\
\text { ( } 97.5 \% \text { bound) }\end{array}$ & 10 Jun & & & & & & \\
\hline $\begin{array}{l}\text { Minimum } \\
\text { ( } 2.5 \% \text { bound) }\end{array}$ & 19 Aug & & & & & & \\
\hline Minimum & $18 \mathrm{Sep}$ & $7 \mathrm{Sep}$ & 31 Aug & 8 Sep & $7 \mathrm{Sep}$ & $20 \mathrm{Sep}$ & $20 \mathrm{Sep}$ \\
\hline $\begin{array}{l}\text { Minimum } \\
\text { ( } 97.5 \% \text { bound) }\end{array}$ & $28 \mathrm{Oct}$ & & & & & & \\
\hline
\end{tabular}

temporal Gaussian filtering, as it results in reduced errors relative to the GRACE-LM filtering method. We consider this to be a statistically conservative approach. Because we are not able to fully capture the effect of filtering on the timing of the seasonal cycle, we choose the filter that brings the timing of the seasonal cycle closer to that of GRACE-LM. Thus, in locations where the timing of the Gaussian-filtered cycle falls outside of the range of dates from GRACE-LM, it is very likely that there is a difference between the modeled and GRACE-LM seasonal cycles that is not associated with filtering. In locations where the timing of the Gaussian-filtered cycle falls within the range of dates from GRACE-LM, we cannot confirm a difference.

\section{Results}

\subsection{Trends and spatial differences in modeled vs. measured mean MB}

We first examine the time series of GrIS cumulative mass as simulated by MAR v3.5.2, ISSM, and GRACE-LM over the 2003-2012 period, as shown in Fig. 6. MAR v3.5.2 cumulative SMB shows a net accumulation of mass over Greenland (of $246.9 \pm 4.7 \mathrm{Gt} \mathrm{yr}^{-1}$ ), which varies seasonally in response to cycles of melting and accumulation. ISSM exhibits a net loss of mass $\left(-425.8 \pm 0.3 \mathrm{Gtyr}^{-1}\right.$ on average), with little seasonal variability relative to the long-term trend. There is a small seasonal cycle in ISSM dynamics driven by the SMB cycle (visible in the detrended time series shown in Fig. S3) which complements the mass changes from MAR (increased

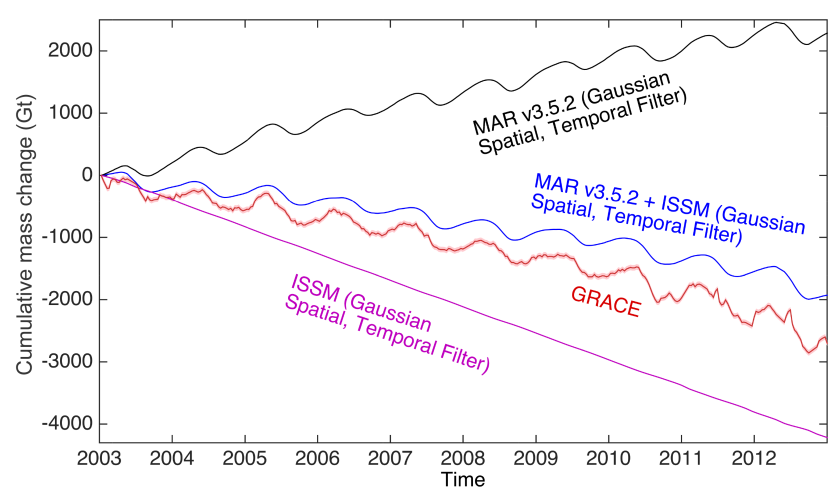

Figure 6. Cumulative GrIS mass change for the January 2003December 2012 period from GRACE-LM, MAR SMB, ISSM DMB, and the combined results of MAR v3.5.2 + ISSM. Spatial and temporal Gaussian filtering is applied to model outputs. The estimated error associated with the GRACE-LM solution is small relative to the overall trend, and is denoted with pink shading surrounding the GRACE-LM time series.

mass loss from MAR leads to decreased mass loss from ISSM, and vice versa), with an amplitude roughly an order of magnitude smaller than the SMB fluctuations. Together, ISSM and MAR v3.5.2 results produce a net loss of mass over 2003-2012, although the trend in simulated mass loss $\left(-178.9 \pm 4.4 \mathrm{Gt} \mathrm{yr}^{-1}\right)$ is smaller in magnitude than that of GRACE-LM $\left(-239.4 \pm 7.7 \mathrm{Gt} \mathrm{yr}^{-1}\right)$ by $60.5 \pm 12.1 \mathrm{Gt} \mathrm{yr}^{-1}$.

The roughly complementary nature of modeled SMB and DMB is evident on a sub ice-sheet-wide scale, as indicated 
by the unfiltered MAR v3.5.2 and ISSM 2003-2012 mean SMB and DMB (Fig. 1) as well as the Gaussian-filtered data (Fig. 7a and b). Areas with a large positive SMB from MAR v3.5.2 show large dynamic mass loss from ISSM (e.g., areas higher than $2000 \mathrm{~m}$ in elevation), while areas with negative SMB from MAR v3.5.2 show smaller losses from ISSM. Summing SMB and DMB from MAR v3.5.2 and ISSM produces the pattern of MB shown in Fig. 7c, which indicates that the majority of modeled mass loss for the 2003-2012 period occurs below $2000 \mathrm{~m}$ in elevation. This is similar to the pattern of MB from GRACE-LM (Fig. 7d). A map of the difference between modeled and GRACE-LM MB (Fig. 7e) indicates that the majority of the difference in trends observed in Fig. 6 results from an underestimation of mass loss from the filtered model results below $2000 \mathrm{~m}$ in elevation, in particular along the west and southeast coasts. Mass loss from GRACE-LM is larger in magnitude along the GrIS margins (by up to $\sim 2.5 \mathrm{Gt} \mathrm{yr}^{-1}$ per mascon). In areas below $2000 \mathrm{~m}$, overall mass loss is underestimated by $92 \pm 10.3 \mathrm{Gt} \mathrm{yr}^{-1}$ (with a trend of $-149.4 \pm 3.5 \mathrm{Gt} \mathrm{yr}^{-1}$ as compared with $-242.4 \pm 6.8 \mathrm{Gt} \mathrm{yr}^{-1}$ from GRACE). For areas above $2000 \mathrm{~m}$, GRACE-LM suggests little change in mass $\left(+3.0 \pm 4.2 \mathrm{Gt} \mathrm{yr}^{-1}\right)$, while the models suggest a loss of $-29.5 \pm 1.0 \mathrm{Gt} \mathrm{yr}^{-1}$. The differences between the models and GRACE-LM are larger than the uncertainties in trends from GRACE-LM and from the model outputs, suggesting that model errors or processes not accounted for contribute to the difference.

The differences between simulated and GRACE-LM MB may be due to a modeled MAR v3.5.2 SMB that is too high below $2000 \mathrm{~m}$ in elevation, or alternately, to simulated velocities that are underestimated in ISSM and vice versa at higher elevations. We evaluate the ISSM spin-up by comparing the ISSM ice thickness at steady state to the ice thickness obtained from the mass conservation data set of Morlighem et al. (2015), derived from radar data for 1993-2014, interpolated onto the ISSM mesh. We also compare ISSM annual ice velocities with the radar-derived ice velocity data of Rignot and Mouginot (2012), derived from data spanning 20082009. A comparison of ice thicknesses from Morlighem et al. (2015) and velocities from Rignot and Mouginot (2012) with ISSM velocities and thicknesses for 1 January 2003 is shown in Fig. S4. Some differences may result from the model outputs and observations not being coincident in time, but Fig. S3 indicates that temporal variability in ISSM is small $(<10 \%)$ relative to long-term changes. (This relatively small variability is to be expected given that the ISSM simulation used here only considers forcing from SMB and not other factors that may lead to larger fluctuations in ice motion.) In particular, ice velocities tend to be underestimated for glaciers along the northwest coast of the GrIS (Fig. S4b), possibly as a consequence of an upstream ice thickness that is also underestimated (Fig. S4a). This may contribute to underestimated mass loss along the northwest coast. In other areas, ice thickness is generally overestimated by ISSM, but
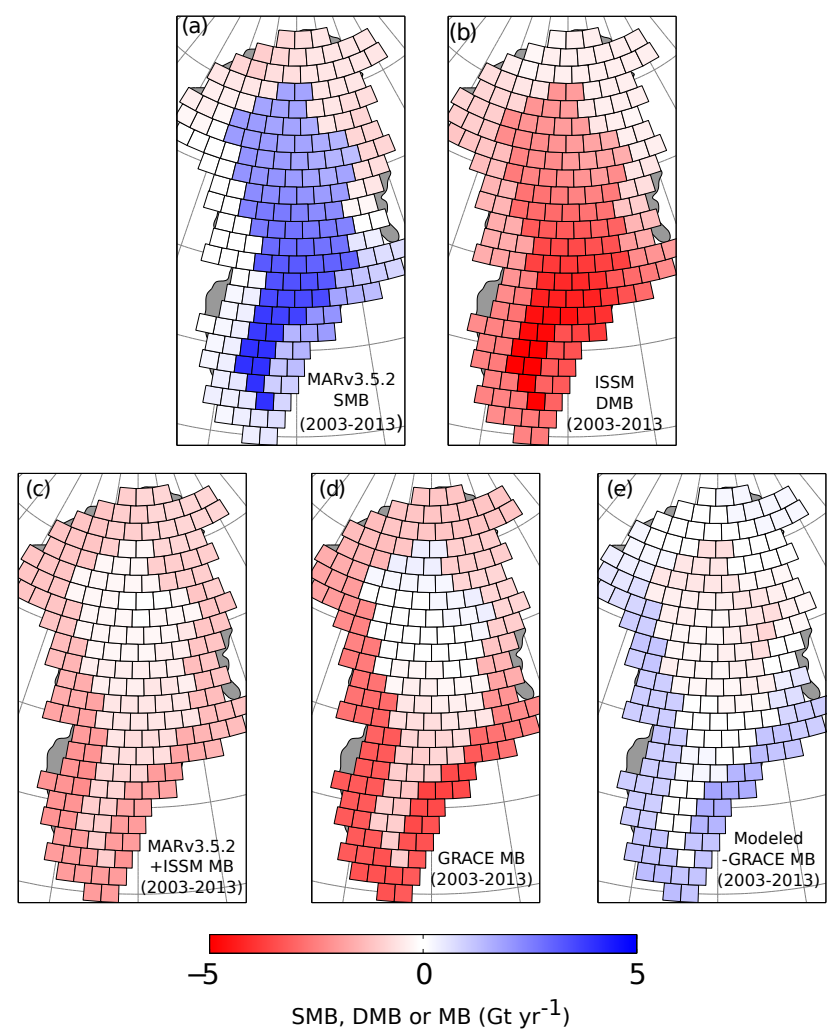

Figure 7. Average January 2003-December 2012 mass balance (Gt) for MAR, ISSM, and GRACE-LM. Gaussian spatial and temporal filtering have been applied to MAR and ISSM outputs. (a) SMB from MAR, (b) dynamic mass change from ISSM, (c) the sum of (a) and (b), giving the mean MB. GRACE-LM mean MB is shown in (d), and (e) depicts the difference between modeled MB (c) and GRACE-LM MB (d).

some outlet glacier velocities are overestimated while others are underestimated, making it unclear how ISSM contributes to the observed discrepancies in these regions. It is difficult to determine if the observed differences are a result of errors in the MAR v3.5.2 SMB forcing (as the spinup relies primarily on the simulated SMB for forcing), simplifications to full-Stokes ice flow in ISSM, processes not considered in the ISSM simulation such as the role of hydrology in ice dynamics and ice-ocean interactions, or errors associated with the assumption that during the spin-up period, the ice sheet is in steady state. The assumption of 2-D flow (the Shelfy-Stream Approximation) in the current ISSM simulation probably contributes to errors in dynamic mass balance, particularly at higher elevations, but it is not clear whether this would lead to faster or slower ice flow. A comparison between MAR v3.5.2 SMB and in situ measurements performed by Colgan et al. (2015) suggests that MAR v3.5.2 does not overestimate SMB below $2000 \mathrm{~m}$, but this comparison is limited to one location in southwest Greenland: the Kangerlussuaq transect (van de Wal et al., 2005), and may not be representative of other areas. Another factor that may 

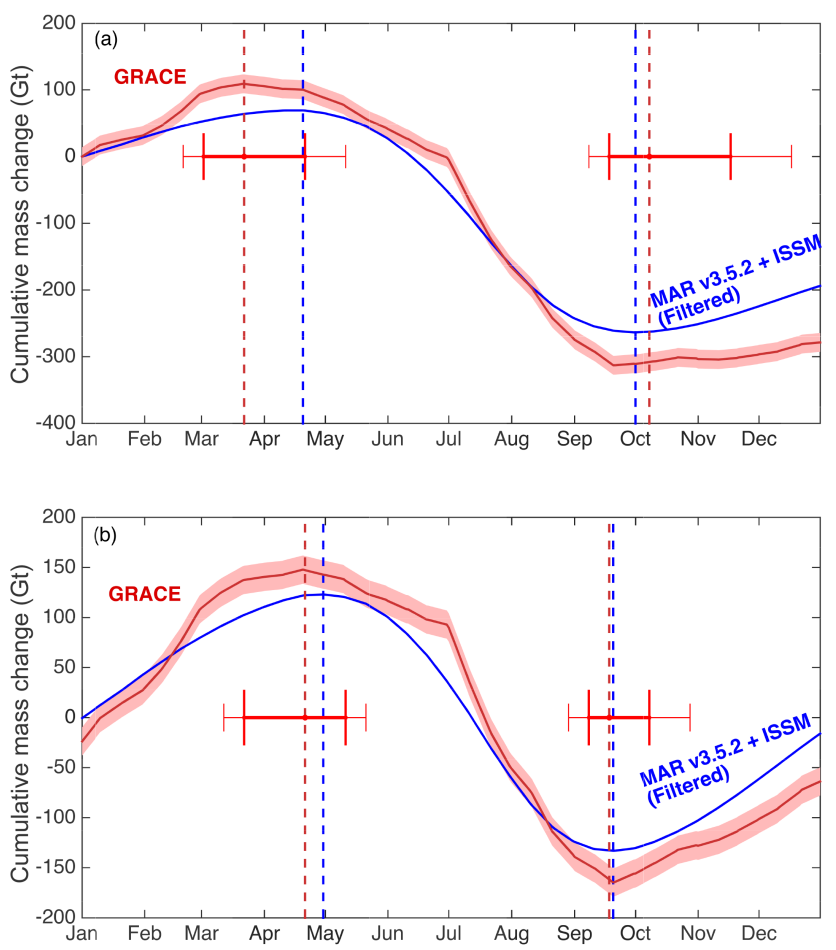

Figure 8. (a) The mean January 2003-December 2012 seasonal cycle of GrIS cumulative mass change from GRACE-LM and MAR v3.5.2 + ISSM. (b) The same as (a) for the case when the time series from all mascons are detrended.

result in the discrepancy between model results and GRACE$\mathrm{LM}$ is the $25 \mathrm{~km}$ resolution of the MAR outputs used in this study. ISSM is forced by a downscaled version of MAR v3.5.2. Using a higher resolution simulation or downscaled outputs could result in different SMB estimates (e.g., Franco et al., 2012). This could be particularly important along the borders of the GrIS, or for mountainous areas outside the ice sheet boundaries. In these areas, high spatial variability of topography can strongly influence SMB. To properly identify the source of the differences, further independent evaluations of MAR SMB and ISSM DMB are needed, for example, comparison between ISSM and remote-sensing-derived discharge estimates (e.g., Rignot and Kanagaratnam, 2006), or comparison between MAR and additional in situ measurements in ablation areas.

\subsection{Seasonal mass changes from MAR, ISSM, and GRACE}

The average seasonal cycle of filtered cumulative MAR v3.5.2 + ISSM for the 2003 through 2012 period agrees well with that of GRACE-LM, as shown in Fig. 8a and Table 2. The amount of mass loss during the period of net ablation is similar for MAR v3.5.2 + ISSM (333 Gt) and GRACE-LM $(355 \pm 32 \mathrm{Gt})$. The dates of simulated maximum and minimum mass fall within the range of uncertainty for these dates from GRACE-LM. It is possible, however, that differences in modeled and GRACE-LM trends alter the timing of the seasonal cycle, because changing the overall trend of a time series can alter the timing of local maxima and minima by altering local rates of change. Therefore, we also show the seasonal cycle for the detrended time series in Fig. $8 \mathrm{~b}$ and Table 2. For the detrended seasonal cycle, the timing of the seasonal maximum occurs roughly 1 month before the maximum peak from the original seasonal cycle, and the timing of the seasonal minimum occurs roughly 1 week earlier (within the uncertainty associated with the $\sim 10$ day GRACE time steps) for both MAR v3.5.2 + ISSM and GRACE-LM. The model timing for the filtered model data falls within the range of dates from GRACE-LM (with and without trends removed), and therefore we cannot confirm any difference between the modeled and GRACE-LM Greenland-wide seasonal cycles of mass change. The results are consistent with the comparison between the detrended MAR v3.5.2 and MAR v2.0 seasonal cycles and GRACE. ISSM makes a small contribution to the simulated seasonal cycle; its seasonal cycle is the inverse of the MAR seasonal cycle with a lag of less than 1 month, indicating that ISSM responds to MAR SMB forcing by increasing discharge during periods of high SMB, and vice versa, with an amplitude roughly an order of magnitude smaller than that of MAR (Fig. S5). As noted earlier, this magnitude of simulated flow variability is the expected response to the SMB forcing applied to ISSM.

\subsection{Spatial variability in the seasonal cycle from MAR, ISSM, and GRACE}

Maps of the timing of peaks in the seasonal cycle of detrended cumulative mass change from GRACE-LM (Fig. 9) suggest that the timing of seasonal cycle peaks is spatially variable. Maps of the median GRACE-LM date for the maximum and minimum peaks (Fig. 9a and d) show that in some locations (e.g., northwest Greenland), GRACE-LM suggests that the peak in the seasonal cycle can occur as early as 1 November (i.e., mass loss begins during the fall), where in other areas it occurs as late as 1 July (for an area in north Greenland). The range of possible dates suggested by GRACE-LM, when taking into account GRACE-LM uncertainty, is fairly large, spanning more than 11 months in some locations in northern Greenland (Fig. 9b, c, e and f) where the magnitude of the seasonal cycle is relatively small, but spatial differences in seasonal timing are preserved even with the large ranges in some areas. The GRACE-LM data suggest that the period of net mass loss begins in fall and ends in early summer in the northwestern portion of the ice sheet, while in most other parts of the ice sheet, mass loss begins in early or late spring, and mass begins to increase again beginning in middle to late autumn. The period of summer mass loss over most of the ice sheet is consistent with what would be expected, given the cycle of climate forcing (warm condi- 
Table 2. Same as Table 1, but for GRACE-LM and MAR v3.5.2 + ISSM (with Gaussian spatial and temporal filtering), for the period January 2003-December 2012.

\begin{tabular}{|c|c|c|c|c|}
\hline & $\begin{array}{l}\text { MAR v3.5.2 } \\
+ \text { ISSM }\end{array}$ & $\begin{array}{l}\text { GRACE } \\
\text { (median and } \\
95 \% \mathrm{CI} \text { ) }\end{array}$ & $\begin{array}{l}\text { GRACE } \\
\text { (median and } \\
95 \% \mathrm{CI} \text {, } \\
\text { detrended) }\end{array}$ & $\begin{array}{l}\text { MAR v3.5.2 } \\
\text { (detrended) }\end{array}$ \\
\hline $\begin{array}{l}\text { Maximum } \\
\text { ( } 2.5 \% \text { bound })\end{array}$ & & $20 \mathrm{Feb}$ & $12 \mathrm{Mar}$ & \\
\hline Maximum & $20 \mathrm{Apr}$ & 22 Mar & $21 \mathrm{Apr}$ & $30 \mathrm{Apr}$ \\
\hline $\begin{array}{l}\text { Maximum } \\
\text { ( } 97.5 \% \text { bound) }\end{array}$ & & 11 May & 21 May & \\
\hline $\begin{array}{l}\text { Minimum } \\
\text { ( } 2.5 \% \text { bound })\end{array}$ & & $8 \mathrm{Sep}$ & 29 Aug & \\
\hline Minimum & $1 \mathrm{Oct}$ & 8 Oct & $18 \mathrm{Sep}$ & $20 \mathrm{Sep}$ \\
\hline $\begin{array}{l}\text { Minimum } \\
\text { ( } 97.5 \% \text { bound) }\end{array}$ & & 17 Dec & $28 \mathrm{Oct}$ & \\
\hline
\end{tabular}
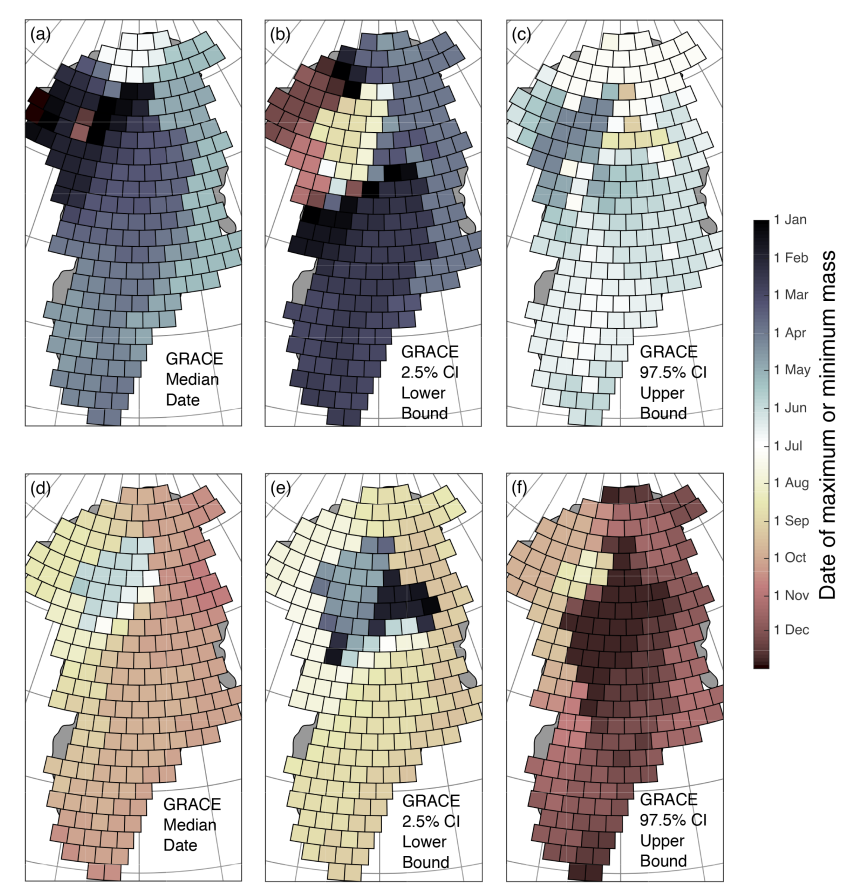

Figure 9. Timing of peaks in the average January 2003-December 2012 seasonal cycle of detrended cumulative mass from GRACELM. (a) Dates of maximum mass for each mascon from the median of the distribution from GRACE-LM, (b) the $2.5 \%$ limit on the distribution of maximum mass dates, and (c) the $97.5 \%$ limit. (d) Dates of minimum mass for each mascon, and (e) the $2.5 \%$ and (f) $97.5 \%$ limits. Ten days have been subtracted (added) to the lower (upper) bound on the distributions to account for potential errors associated with temporal resolution. tions leading to increased melt), but the timing of the cycle in the northwest suggests that other processes may dominate seasonal variability in that region.

MAR v3.5.2 + ISSM suggest a more uniform pattern of timing in seasonal cycle peaks (Fig. 10a, b), consistent with the SMB forcing. The filtered model results suggest that mass loss begins in late spring and early summer (between March and June) without much spatial variability across the ice sheet, and mass gain commences in late summer and early fall (between September and November), with the period of mass loss ending $\sim 1$ month later for mascons below $2000 \mathrm{~m}$ in elevation relative to those above $2000 \mathrm{~m}$ in elevation. These results are consistent with what would be expected given warmer temperatures at lower elevations and a longer period available for melting. (The differences are also likely to be larger without filtering.)

For many mascons in the northwest, the modeled cycle maximum and minimum peaks can occur up to 3 months after and 2 months before the GRACE-LM peaks (Fig. 10c, d), with differences of $\sim 1$ month being quite common. Given the relatively large uncertainty in the timing of the GRACELM peaks, the model peaks often fall within the distribution of peaks from GRACE-LM. Along a portion of the northwest coast, however, the timing of the seasonal maximum occurs in May according to the models, roughly 1 or 2 months after the $95 \%$ confidence limit on the timing of maximum mass from GRACE-LM, and more than 3 months after the median peak from GRACE-LM. The clustering of the GRACE-LM peaks, despite the large uncertainty in the GRACE timing, suggests that the observed variations in timing are not associated with random deviations between mascons, but reflect seasonal variations in mass detected by GRACE-LM, that are not captured by the models. The timing of seasonal minimum 

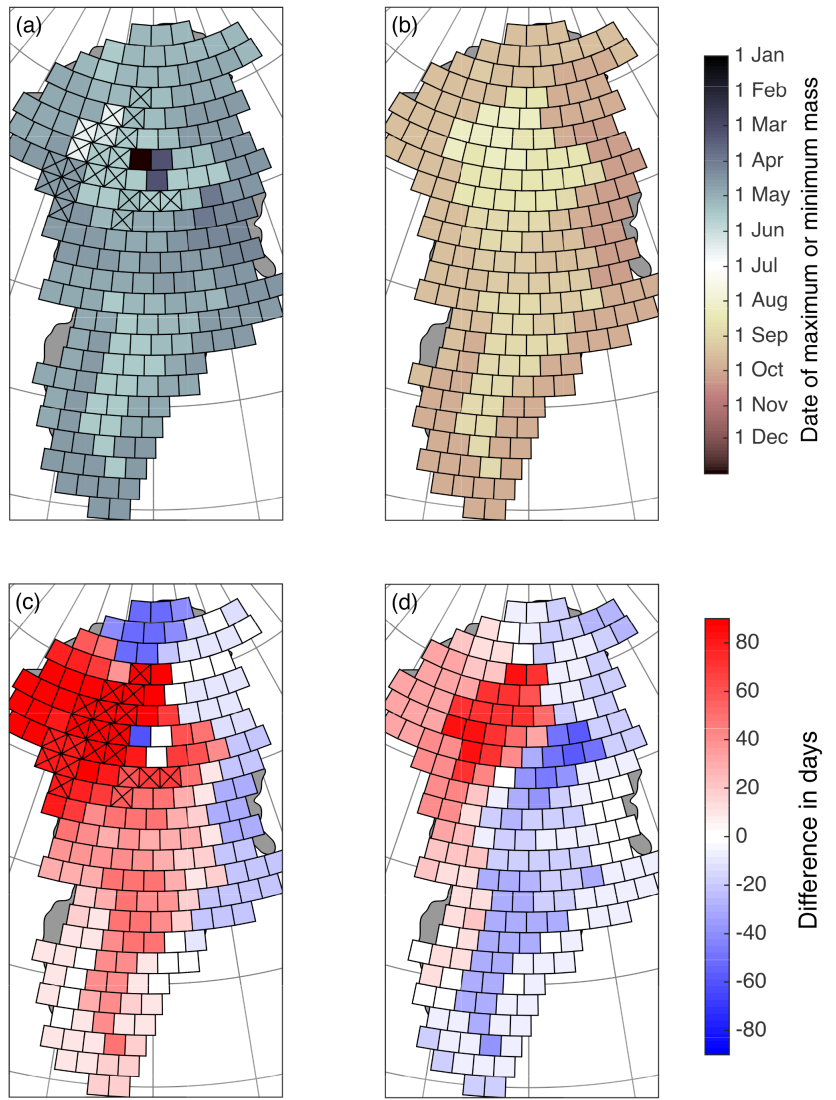

Figure 10. Timing in peaks of the seasonal cycle of detrended cumulative MB simulated by GRACE-LM-filtered MAR v3.5.2 + ISSM outputs. (a) The timing of the maximum peak for each mascon, and (b) the timing of the minimum peak for each mascon. The number of days between MAR v3.5.2 + ISSM and the GRACELM median dates for the cycle maximum and minimum are shown in (c) and (d) respectively. For (c) and (d), red colors indicate that the model date occurs later than that of GRACE-LM, and blue colors indicate an earlier date. " $\mathrm{x}$ " marks indicate where the modeled peak falls outside of the error range of dates for the GRACE-LM peak shown in Fig. 9.

falls within $95 \%$ of the distribution from GRACE-LM for all mascons.

\subsection{The average seasonal cycle within ice sheet subregions}

In order to further examine discrepancies at regional scales, we created nine subregions of the GrIS based on the median timing of the maximum and minimum peaks of the average detrended annual cycle from GRACE-LM (Fig. 9a and d). Mascons were grouped together if the timing of their maximum and minimum peaks were within 34 days of each other. (The threshold was chosen to create a balance between different types of cyclical patterns and the total number of regions.) The nine subregions are shown in Fig. 11a, along with the average seasonal cycle from four of these subre-
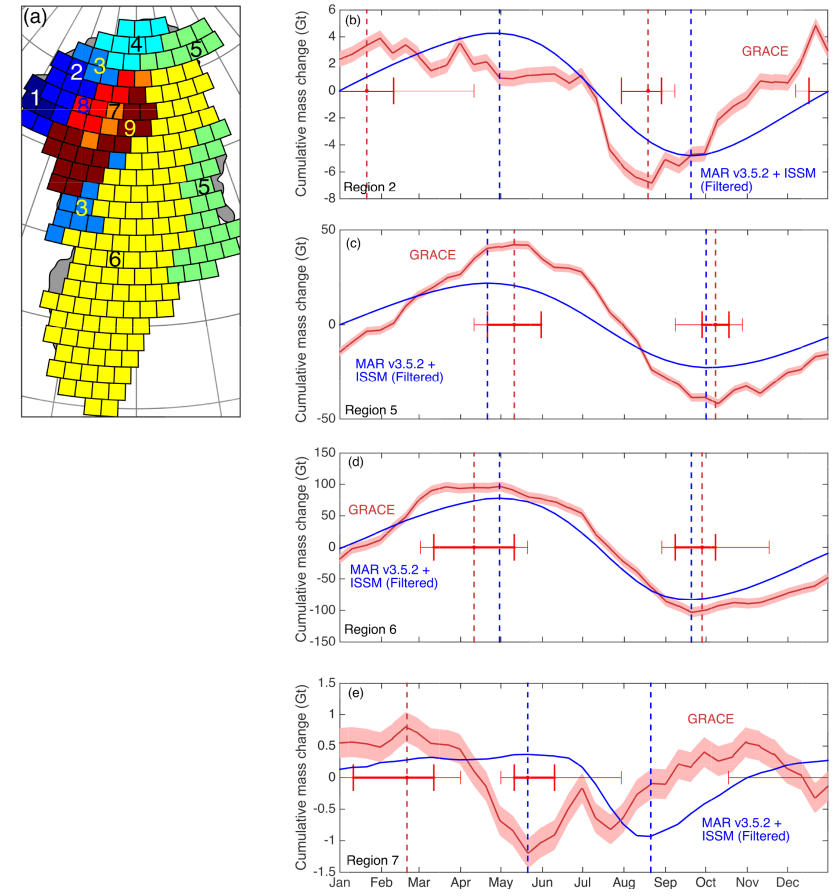

Figure 11. (a) GrIS regions defined based on the timing of peaks in the average cycle of detrended cumulative mass change from GRACE-LM. The average January 2003 to December 2012 seasonal cycle from MAR v3.5.2 + ISSM and GRACE-LM is also shown for selected regions: (b) Region 2, (c) Region 5, (d) Region 6, and (e) Region 7.

gions (Fig. 11b-e). The average cycles for other regions are provided in Fig. S6a-e. The average GRACE-LM seasonal cycle for Region 2 significantly differs in its timing from the MAR v3.5.2 + ISSM cycle. GRACE-LM results suggest that the period of net mass loss begins no later than mid-April, while the models suggest that it begins in early May as a result of the SMB signal. For Region 7 (Fig. 11e), the difference in timing is larger. The maximum in the cycle of cumulative mass change occurs in mid-May (although the ice sheet does not appear to start losing a substantial amount of mass until late June), while the GRACE-LM peak occurs in mid-February. The entire modeled cycle appears to be offset by 3 months relative to GRACE-LM in this region, although seasonal mass changes are relatively small (on the order of $5 \mathrm{Gt}$ ). For Regions 8 and 9 (Fig. S6d and e), the timing of the GRACE-LM and modeled peaks is similar to that of Region 7, with the exception that in Region 9, the minimum GRACE-LM peak overlaps with a September minimum peak from the models. For Regions 5 and 6 (Fig. 11c and d), the model maximum and minimum peaks fall within the distribution for GRACE-LM peaks. For Regions 1 and 3 (Fig. S6a and b), the cycles are similar to those of Region 2, with model peaks falling within the distribution from GRACE-LM for Region 3. For Region 4 (Fig. S6c), the cycle is similar to the cycle of Region 6, except for a sharp peak in mass in early 
July, which leads the GRACE-LM peak to occur after the peak from the models.

Dividing the GrIS into high- and low-elevation areas (above and below $2000 \mathrm{~m}$ in elevation) also produces differences in the seasonal cycle (Fig. 12). For areas below $2000 \mathrm{~m}$ in elevation (Fig. 12a), there is a good agreement between the GRACE-LM and simulated seasonal cycles; the timing of MAR v3.5 + ISSM maximum and minimum peaks falls within the distribution of peaks for GRACE-LM as the signal is dominated by the summer surface mass loss. For areas higher than $2000 \mathrm{~m}$ in elevation (Fig. 12b), the period of simulated net mass loss is shortened relative to that of GRACE-LM. The good agreement between cycles at low elevations suggests that the timing of ablation and accumulation at low elevations on an ice-sheet-wide scale is well captured by MAR v3.5.2 + ISSM.

As in the case of Greenland-wide fluctuations in mass, most of the simulated seasonal variability within subregions of the ice sheet is dominated by MAR, as expected given that the only forcing applied to ISSM is the SMB from MAR. ISSM exhibits a seasonal cycle that is a lagged inverse of the MAR cycle with less than $10 \%$ of the amplitude of MAR v3.5.2 in all subregions of the ice sheet (Figs. S7, S8, and S9), and the seasonal response is consistent across all areas of the ice sheet. The timing of the seasonal cycle for GRACE, MAR v3.5.2, ISSM, and MAR v3.5.2 + ISSM for all subregions is provided in Table $\mathrm{S} 1$ in the Supplement.

The differences in the GRACE-LM and modeled seasonal cycles within individual regions seem unlikely to be caused by errors in the simulated timing of surface ablation, as they occur during times of the year when melting does not occur at the surface (i.e., the "early" start to the period of net mass loss in the northwest from November through February; Fig. 9a, b, c). The results therefore suggest that the observed changes could be associated with errors in seasonal accumulation from MAR v3.5.2, or processes not currently incorporated into ISSM, which induce seasonal fluctuations in ice discharge or liquid water. These processes are difficult to validate, and therefore it is difficult to determine which processes are most responsible for the observed differences. As discussed in the following section, significant seasonal variations in glacier velocities have been observed and could contribute to the observed discrepancies. Accumulation or ice flow errors could also affect differences at higher elevations, where the net ablation due to melting is small (i.e., above $2000 \mathrm{~m}$ in elevation). Such discrepancies could also be influenced by differences below $2000 \mathrm{~m}$ due to leakage between constraint regions, but the amount of leakage in terms of amplitude is small and is comparable to the GRACE-LM uncertainty (Luthcke et al., 2013). Additionally, it is possible that although the GRACE-LM solution includes error estimates associated with the forward models used in GRACE processing, errors or processes not accounted for, such as errors in model simulations used to correct for variability in atmospheric or ocean circulation (for which observations
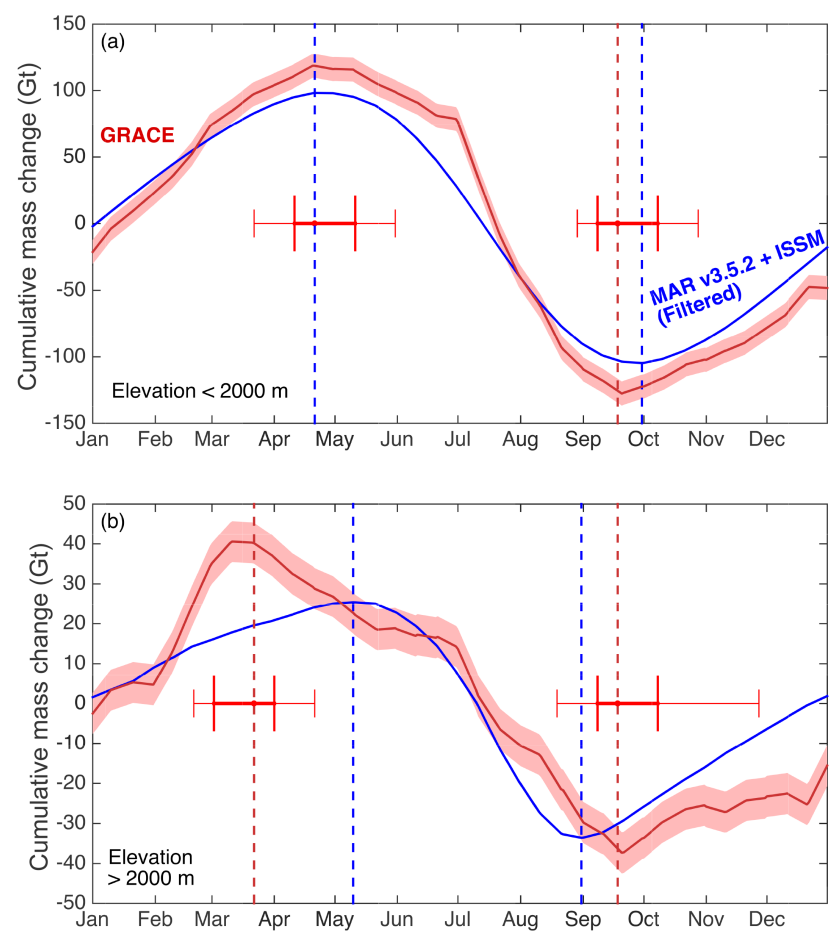

Figure 12. Same as Fig. 8 b, but for (a) regions below $2000 \mathrm{~m}$ in elevation, and (b) above $2000 \mathrm{~m}$ in elevation.

for validation are limited), may contribute to the differences. However, we cannot envision any obvious reason for the discrepancy other than the potential errors in ISSM or MAR v3.5.2 that have been noted.

\section{Concluding remarks}

The above results show several areas of agreement as well as areas of disagreement between modeled and GRACEderived Greenland mass balance. We have shown that in order to compare spatial and temporal variations in GrIS mass from RCM, ISM results, and the GRACE-LM solution, it is necessary to spatially and temporally filter the model outputs. We have developed a Gaussian approximation to the GRACE-LM resolution operator, which accurately captures the effect of the GRACE-LM solution on spatial variations in mean MB. We also find that applying temporal filtering reduces differences between the modeled and GRACE-LM seasonal cycles. We have therefore also applied a temporal Gaussian filter to the model outputs to reproduce the attenuation inherent to GRACE-LM processing. The Gaussian temporal filtering does not completely capture the seasonal cycle of mass changes obtained using the GRACE-LM resolution operator in that it extends the period of mass loss simulated by the models further than the period obtained from GRACELM filtering. As the filter extends the length of the modeled period of mass loss, and tends to bring the timing of mod- 
eled seasonal cycle peaks closer to those from GRACE-LM (which exhibits a longer period of mass loss relative to the unfiltered model results), our approach is conservative: in cases where the cycles disagree, there is likely a difference between the GRACE-LM and modeled seasonal cycles.

A comparison between Gaussian-filtered MAR v3.5.2 + ISSM and GRACE-LM Greenland mass trends for 20032012 indicates that the models tend to underestimate the magnitude of this mass loss, as a result of underestimated mass loss below $2000 \mathrm{~m}$ in elevation. This difference is either due to an overestimation of SMB from MAR v3.5.2 in low-elevation areas, or to intrinsic errors in ice flow from ISSM. MAR v3.5.2 SMB for low-elevation areas is higher than that of MAR v2.0, in part due to a relatively high bare ice albedo (as described by Alexander et al., 2014; a higher albedo persists despite modifications made to MAR v3.5.2 albedo), and in part due to a shift in precipitation from highto low-elevation areas. A comparison at eight in situ stations at the Kangerlussuaq transect on the southwest GrIS suggests that MAR v3.5.2 SMB is closer to in situ measurements (Colgan et al., 2015), but such measurements are limited to this transect with the exception of a comparable number of ablation stake measurements from the Programme for Monitoring of the Greenland Ice Sheet (PROMICE, 2016). The only means of determining the relative contribution of ISSM and MAR v3.5.2 to underestimated mass loss would be to conduct an independent evaluation of each model against DMB (e.g., using the methods of Rignot and Kanagaratnam, 2006) and SMB estimates over large portions of the GrIS. These analyses are beyond the scope of this study, and the evaluation of SMB is limited by sparsely available data, although radar measurements of snow accumulation may help to fill this gap. A preliminary comparison by Koenig et al. (2015) suggests that there is a good agreement between MAR v3.5.2 and radar-derived accumulation estimates over the interior of the GrIS during the years 2009-2012, but that MAR tends to overestimate accumulation along the southeastern coast.

We examined the mean seasonal cycles of detrended cumulative mass change from GRACE-LM and MAR v3.5.2 + ISSM as a means of examining the ability of the models to capture mass changes at a relatively high spatial and temporal resolution. We have shown that on a Greenland-wide scale, the timing of modeled and GRACE seasonal cycles agree, within the limits of GRACE uncertainty, but on subice-sheet-wide scales, there are significant differences in the timing of annual cycle peak. On the scale of individual mascons, there is considerable variability in the timing of the seasonal cycle from GRACE-LM, while model outputs suggest a more uniform timing across Greenland driven mainly by summer surface mass loss and mass gain simulated by MAR. While some of this variability is likely due to GRACE errors, other variations likely reflect real differences in the seasonal variability within different regions, particularly as the differences are not random, but spatially clustered. In particular, in northwestern Greenland, the simulated period of mass loss is shorter than that of GRACE-LM, and the timing of the simulated maximum in the seasonal cycle occurs up to 3 months after the GRACE-LM peak in some areas.

Spatial and seasonal differences in the seasonal cycle may result from various factors including (1) underestimation or overestimation of accumulation and ablation by MAR v3.5.2, (2) cycles of ice sheet motion associated with processes not incorporated into ISSM, (3) cycles of water storage and release, and (4) errors in the GRACE-LM solution. We have attempted to account for the last factor by considering the impact of errors of the GRACE-LM solution estimated by Luthcke et al. (2013) on the timing of the seasonal cycle, and by filtering our model results to match GRACE-LM. However, as GRACE does not provide direct observations of mass changes, and different methods of processing can produce somewhat different mass change solutions (Shepherd et al., 2012), it is possible that some of the observed discrepancies may be due to errors not considered in this solution. With regard to MAR v3.5.2 accumulation, the Colgan et al. (2015) study suggests that MAR v3.5.2 effectively captures spatial variations in SMB, but few observations of SMB are available in areas of net ablation. The seasonal cycle of MAR v3.5.2 has not been evaluated against observations, as few sub-annual estimates of accumulation are available. With regard to GrIS discharge, an analysis of ISSM annual discharge has not been conducted, although comparison with satellite-derived ice velocities suggests that ISSM velocities may be underestimated in some areas at the ice sheet margins. Data on seasonal velocities are not available for the entire GrIS, but various studies have indicated that seasonal variations in the flow of GrIS glaciers occur, particularly in association with meltwater that reaches the ice sheet bed (e.g., Joughin et al., 2008), as well as interactions between ocean circulation and ice at calving fronts (Howat et al., 2010). Using GPS measurements for west coast GrIS glaciers, Ahlstrøm et al. (2013) showed that the glaciers examined underwent seasonal cycles in velocity, with several glaciers showing a decline in velocity in late summer associated with increased efficiency of subglacial drainage systems. Moon et al. (2014) present the most comprehensive evaluation of seasonal velocity cycles to date, identifying three types of seasonal cycles in velocity near the terminus of marine-terminating glaciers, one in which meltwater production produces acceleration during summer months (type 2 ), another in which deceleration occurs late in the melt season, followed by acceleration peaking in the early melt season (type 3), and a third in which fluctuations are more likely associated with ice-ocean interactions (type 1). Different glaciers exhibit different patterns of flow variability, and a single glacier may exhibit different patterns of flow in different years. Seasonal variations in flow generally represent $\sim 10-20 \%$ of mean annual velocities. The type 1 and especially type 3 seasonal patterns could potentially lead to the patterns of mass change from GRACE-LM in northwest Greenland, but it is unclear how variations in flow of differ- 
ent glaciers contribute to seasonal fluctuations in ice sheet discharge, and a study examining this would be useful for evaluating ISMs such as ISSM, which do not currently take into account the influence of these processes.

The general agreement between modeled and GRACELM MB below $2000 \mathrm{~m}$ in elevation, where ice sheet hydrology might be expected to play a role, suggests that factors such as water storage and release as indicated by Rennermalm et al. (2013), and observed on glaciers in locations outside of Greenland (Jansson et al., 2003), do not play a large role in the timing of seasonal variations in mass on the icesheet-wide scale. It is possible that these processes influence the amplitude of mass variations, or lead to changes in mass on shorter timescales that we cannot observe given the uncertainties in GRACE-LM results and filtering, and that they play a role in longer-term variations in mass. Long-term water storage could contribute to underestimated trends in mass loss below $2000 \mathrm{~m}$ in elevation, which could also result from underestimated SMB from MAR v3.5.2, or an underestimation of $D$ from ISSM.

Further studies are also needed to understand the impact of temporal variations in mass on the observations presented here, i.e., whether they are associated with processes that reoccur from year-to-year, or whether isolated events influence the timing of the seasonal cycle. In addition, future studies are needed to validate seasonal variations of RCM accumulation and simulated SMB in ablation areas. The spatial and temporal resolution of this analysis was limited by the fundamental spatial and temporal resolutions of GRACE to seasonal-scale variability and spatial scales of $\sim 600 \mathrm{~km}$. It is possible that if seasonal variations in GrIS mass are examined at higher spatial and temporal resolutions, with reduced errors, further discrepancies between modeled and measured cycles will be observed. As the ice sheet changes in the future, such processes could potentially become more important to GrIS-wide changes in mass, and therefore they need to be better understood and their impact quantified.

\section{Data availability}

The latest up-to-date version of the Luthcke et al. (2013) GRACE mascon solution is publically available at $\mathrm{http}: / /$ ssed.gsfc.nasa.gov/grace. This version is an updated version of the data set used in this study. The older version of the Luthcke et al. (2013) solution used in this study is available upon request from scott.b.luthcke@nasa.gov or patrick.m.alexander@nasa.gov. MAR v3.5.2 model outputs used in this study are available online at $\mathrm{ftp} / / / \mathrm{ftp} . c l i m a t o . b e / f e t t w e i s / M A R v 3.5 /$ Greenland/ERA 1958-2014_25km/monthly_raw_outputs_at_25km/. MAR v2.0 daily model outputs used in this study are available upon request from patrick.m.alexander@nasa.gov or xavier.fettweis@ulg.ac.be. ISSM model outputs used in this study are available upon request from the ISSM model team (issm@jpl.nasa.gov or http://issm.jpl.nasa.gov/contactus/). MATLAB code used to aggregate and filter model results is also available upon request from patrick.m.alexander@nasa.gov.

\section{The Supplement related to this article is available online at doi:10.5194/tc-10-1259-2016-supplement.}

Author contributions. P. M. Alexander and M. Tedesco devised the study. P. M. Alexander carried out the analysis. N.-J. Schlegel and E. Larour performed simulations with the ISSM model. N.J. Schlegel and E. Larour also contributed to the development of ISSM. S. B. Luthcke produced the GRACE solution. X. Fettweis performed simulations with the MAR model. X. Fettweis also contributed to the development of MAR. P. M. Alexander prepared the manuscript. All co-authors revised and contributed to the editing of the manuscript.

Acknowledgements. P. M. Alexander and M. Tedesco were supported by NSF grant PLR no. 0909388. Work of N.-J. Schlegel and E. Larour was performed at the California Institute of Technology's Jet Propulsion Laboratory under a contract with the National Aeronautics and Space Administration's Cryosphere Program. The authors would like to thank Rajashree Datta, Erik Noble, and Erik Orantes of the Cryospheric Processes Laboratory, two anonymous reviewers, and the editor of this manuscript for valuable comments and suggestions.

Edited by: O. Eisen

\section{References}

Ahlstrøm, A. P., Andersen, S. B., Andersen, M. L., Machguth, H., Nick, F. M., Joughin, I., Reijmer, C. H., van de Wal, R. S. W., Merryman Boncori, J. P., Box, J. E., Citterio, M., van As, D., Fausto, R. S., and Hubbard, A.: Seasonal velocities of eight major marine-terminating outlet glaciers of the Greenland ice sheet from continuous in situ GPS instruments, Earth Syst. Sci. Data, 5, 277-287, doi:10.5194/essd-5-277-2013, 2013.

Alexander, P. M., Tedesco, M., Fettweis, X., van de Wal, R. S. W., Smeets, C. J. P. P., and van den Broeke, M. R.: Assessing spatiotemporal variability and trends in modelled and measured Greenland Ice Sheet albedo (2000-2013), The Cryosphere, 8, 22932312, doi:10.5194/tc-8-2293-2014, 2014.

Bartholomew, I., Nienow, P., Mair, D., Hubbard, A., King, M. A., and Sole, A.: Seasonal evolution of subglacial drainage and acceleration in a Greenland outlet glacier, Nat. Geosci., 3, 408-411, doi:10.1038/ngeo863, 2010.

Box, J. E.: Greenland Ice Sheet Mass Balance Reconstruction. Part II: Surface Mass Balance (1840-2010), J. Clim., 26, 6974-6989, doi:10.1175/JCLI-D-12-00518.1, 2013. 
Box, J. E., Cressie, N., Bromwich, D. H., Jung, J.-H., van den Broeke, M., van Angelen, J. H., Forster, R. R., Miège, C., Mosley-Thompson, E., Vinther, B., and McConnell, J. R.: Greenland Ice Sheet Mass Balance Reconstruction. Part I: Net Snow Accumulation (1600-2009), J. Clim., 26, 3919-3934, doi:10.1175/JCLI-D-12-00373.1, 2013.

Brun, E., David, P., Sudul, M., and Brunot, G.: A numerical model to simulate snow-cover stratigraphy for operational avalanche forecasting, J. Glaciol., 38, 13-22, 1992.

Chu, V. W.: Greenland ice sheet hydrology: A review, Prog. Phys. Geogr., 38, 19-54, doi:10.1177/0309133313507075, 2014.

Colgan, W., Box, J. E., Andersen, M. L., Fettweis, X., Csathó, B., Fausto, R. S., van As, D., and Wahr, J.: Greenland highelevation mass balance: inference and implication of reference period (1961-90) imbalance, Ann. Glaciol., 56, 105-117, doi:10.3189/2015AoG70A967, 2015.

Cuffey, K. M. and Paterson, S. B.: Chapter 4: Mass Balance Processes: 1. overview and regimes, in: The Physics of Glaciers, Academic Press, Oxford, UK, 91-136, 2011.

Das, S. B., Joughin, I., Behn, M. D., Howat, I. M., King, M. A., Lizarralde, D., and Bhatia, M. P.: Fracture Propagation to the Base of the Greenland Ice Sheet During Supraglacial Lake Drainage, Science, 320, 778-781, doi:10.1126/science.1153360, 2008.

Dee, D. P., Uppala, S. M., Simmons, A. J., Berrisford, P., Poli, P., Kobayashi, S., Andrae, U., Balmaseda, M. A., Balsamo, G., Bauer, P., Bechtold, P., Beljaars, A. C. M., van de Berg, L., Bidlot, J., Bormann, N., Delsol, C., Dragani, R., Fuentes, M., Geer, A. J., Haimberger, L., Healy, S. B., Hersbach, H., Hólm, E. V., Isaksen, L., Kållberg, P., Köhler, M., Matricardi, M., McNally, A. P., Monge-Sanz, B. M., Morcrette, J.-J., Park, B.-K., Peubey, C., de Rosnay, P., Tavolato, C., Thépaut, J.-N., and Vitart, F.: The ERA-Interim reanalysis: configuration and performance of the data assimilation system, Q. J. Roy. Meteorol. Soc., 137, 553597, doi:10.1002/qj.828, 2011.

Ettema, J., van den Broeke, M. R., van Meijgaard, E., van de Berg, W. J., Bamber, J. L., Box, J. E., and Bales, R. C.: Higher surface mass balance of the Greenland ice sheet revealed by highresolution climate modeling, Geophys. Res. Lett., 36, L12501, doi:10.1029/2009GL038110, 2009.

Fettweis, X.: Reconstruction of the 1979-2006 Greenland ice sheet surface mass balance using the regional climate model MAR, The Cryosphere, 1, 21-40, doi:10.5194/tc-1-21-2007, 2007.

Fettweis, X., Hanna, E., Lang, C., Belleflamme, A., Erpicum, M., and Gallée, H.: Brief communication "Important role of the midtropospheric atmospheric circulation in the recent surface melt increase over the Greenland ice sheet", The Cryosphere, 7, 241248, doi:10.5194/tc-7-241-2013, 2013a.

Fettweis, X., Franco, B., Tedesco, M., van Angelen, J. H., Lenaerts, J. T. M., van den Broeke, M. R., and Gallée, H.: Estimating the Greenland ice sheet surface mass balance contribution to future sea level rise using the regional atmospheric climate model MAR, The Cryosphere, 7, 469-489, doi:10.5194/tc-7-469-2013, 2013b.

Forster, R. R., Box, J. E., van den Broeke, M. R., Miège, C., Burgess, E. W., van Angelen, J. H., Lenaerts, J. T. M., Koenig, L. S., Paden, J., Lewis, C., Gogineni, S. P., Leuschen, C., and McConnell, J. R.: Extensive liquid meltwater storage in firn within the Greenland ice sheet, Nat. Geosci., 7, 95-98, doi:10.1038/ngeo2043, 2013.

Franco, B., Fettweis, X., Lang, C., and Erpicum, M.: Impact of spatial resolution on the modelling of the Greenland ice sheet surface mass balance between 1990-2010, using the regional climate model MAR, The Cryosphere, 6, 695-711, doi:10.5194/tc6-695-2012, 2012.

Franco, B., Fettweis, X., and Erpicum, M.: Future projections of the Greenland ice sheet energy balance driving the surface melt, The Cryosphere, 7, 1-18, doi:10.5194/tc-7-1-2013, 2013.

Gallée, H.: Air-sea interactions over Terra Nova Bay during winter: simulation with a coupled atmosphere-polynya model, J. Geophys. Res., 102, 13835-13849, 1997.

Gallée, H. and Schayes, G.: Development of a three-dimensional meso- $\gamma$ primitive equation model: katabatic winds simulation in the area of Terra Nova Bay, Antarctica, Mon. Weather Rev., 122, 671-685, 1994.

Hoffman, M. J., Catania, G. A., Neumann, T. A., Andrews, L. C., and Rumrill, J. A.: Links between acceleration, melting, and supraglacial lake drainage of the western Greenland Ice Sheet, J. Geophys. Res., 116, F04035, doi:10.1029/2010JF001934, 2011.

Howat, I. M., Box, J. E., Ahn, Y., Herrington, A., and McFadden, E. M.: Seasonal variability in the dynamics of marine-terminating outlet glaciers in Greenland, J. Glaciol., 56, 601-613, 2010.

Huybrechts, P., Goelzer, H., Janssens, I., Driesschaert, E., Fichefet, T., Goosse, H., and Loutre, M.-F.: Response of the Greenland and Antarctic Ice Sheets to Multi-Millennial Greenhouse Warming in the Earth System Model of Intermediate Complexity LOVECLIM, Surv. Geophys., 32, 397-416, doi:10.1007/s10712-0119131-5, 2011.

Jansson, P., Hock, R., and Schneider, T.: The concept of glacier storage: a review, J. Hydrol., 282, 116-129, doi:10.1016/S00221694(03)00258-0, 2003.

Joughin, I., Das, S. B., King, M. A., Smith, B. E., Howat, I. M., and Moon, T.: Seasonal Speedup Along the Western Flank of the Greenland Ice Sheet, Science, 320, 781-783, doi:10.1126/science.1153288, 2008.

Joughin, I., Smith, B. E., Shean, D. E., and Floricioiu, D.: Brief Communication: Further summer speedup of Jakobshavn Isbræ, The Cryosphere, 8, 209-214, doi:10.5194/tc-8-209-2014, 2014.

Koenig, L. S., Miège, C., Forster, R. R., and Brucker, L.: Initial in situ measurements of perennial meltwater storage in the Greenland firn aquifer, Geophys. Res. Lett., 41, 81-85, doi:10.1002/2013GL058083, 2014.

Koenig, L. S., Ivanoff, A., Alexander, P. M., MacGregor, J. A., Fettweis, X., Panzer, B., Paden, J. D., Forster, R. R., Das, I., McConnell, J., Tedesco, M., Leuschen, C., and Gogineni, P.: Annual Greenland accumulation rates (2009-2012) from airborne Snow Radar, The Cryosphere Discuss., 9, 6697-6731, doi:10.5194/tcd9-6697-2015, 2015.

Larour, E., Seroussi, H., Morlighem, M., and Rignot, E.: Continental scale, high order, high spatial resolution, ice sheet modeling using the Ice Sheet System Model (ISSM), J. Geophys. Res., 117, F01022, doi:10.1029/2011JF002140, 2012.

Lefebre, F., Gallée, H., van Ypersele, J.-P., and Greuell, W.: Modeling of snow and ice melt at ETH Camp (West Greenland): a study of surface albedo, J. Geophys. Res., 108, 4321, doi:10.1029/2001JD001160, 2003. 
Luthcke, S. B., Zwally, H. J., Abdalati, W., Rowlands, D. D., Ray, R. D., Nerem, R. S., Lemoine, F. G., McCarthy, J. J., and Chinn, D. S.: Recent Greenland Ice Mass Loss by Drainage System from Satellite Gravity Observations, Science, 314, 1286-1289, doi:10.1126/science.1130776, 2006.

Luthcke, S. B., Sabaka, T. J., Loomis, B. D., Arendt, A. A., McCarthy, J. J., and Camp, J.: Antarctica, Greenland and Gulf of Alaska land-ice evolution from an iterated GRACE global mascon solution, J. Glaciol., 59, 613-631, doi:10.3189/2013JoG12J147, 2013.

MacAyeal, D. R.: Large-scale ice flow over a viscous basal sediment: theory and application to ice stream B, Antarctica, J. Geophys. Res., 94, 4071-4087, 1989.

Moon, T., Joughin, I., Smith, B., van den Broeke, M. R., van de Berg, W. J., Noël, B., and Usher, M.: Distinct patterns of seasonal Greenland glacier velocity: Seasonal velocity, Geophys. Res. Lett., 41, 7209-7216, doi:10.1002/2014GL061836, 2014.

Morlighem, M., Rignot, E., Seroussi, H., Larour, E., Ben Dhia, H., and Aubry, D.: Spatial patterns of basal drag inferred using control methods from a full-Stokes and simpler models for Pine Island Glacier, West Antarctica, Geophys. Res. Lett., 37, L14502, doi:10.1029/2010GL043853, 2010.

Morlighem, M., Rignot, E., Mouginot, J., Seroussi, H., and Larour, E.: High-resolution ice-thickness mapping in South Greenland, Ann. Glaciol., 55, 64-70, doi:10.3189/2014AoG67A088, 2014.

Morlighem, M., Rignot, E., Bouginot, J., Seroussi, H., and Larour, E.: IceBridge BedMachine Greenland, Version 2. Boulder Colorado USA. NASA National Snow and Ice Data Center Distributed Active Archive Center, doi:10.5067/AD7B0HQNSJ29, 2015.

Nghiem, S. V., Hall, D. K., Mote, T. L., Tedesco, M., Albert, M. R., Keegan, K., Shuman, C. A., DiGirolamo, N. E., and Neumann, G.: The extreme melt across the Greenland ice sheet in 2012, Geophys. Res. Lett., 39, L20502, doi:10.1029/2012GL053611, 2012.

Programme for Monitoring of the Greenland Ice Sheet (PROMICE): Historical mass balance data, available at: http://www.promice.org/MassebalancedataDownload.html, last access: 7 June 2016.

Quiquet, A., Punge, H. J., Ritz, C., Fettweis, X., Gallée, H., Kageyama, M., Krinner, G., Salas y Mélia, D., and Sjolte, J.: Sensitivity of a Greenland ice sheet model to atmospheric forcing fields, The Cryosphere, 6, 999-1018, doi:10.5194/tc-6-9992012, 2012.

Rennermalm, A. K., Smith, L. C., Chu, V. W., Box, J. E., Forster, R. R., Van den Broeke, M. R., Van As, D., and Moustafa, S. E.: Evidence of meltwater retention within the Greenland ice sheet, The Cryosphere, 7, 1433-1445, doi:10.5194/tc-7-1433-2013, 2013.

Rignot, E. and Kanagaratnam, P.: Changes in the velocity structure of the Greenland Ice Sheet, Science, 311, 986-990, doi:10.1126/science.1121381, 2006.

Rignot, E. and Mouginot, J.: Ice flow in Greenland for the International Polar Year 2008-2009, Geophys. Res. Lett., 39, L11501, doi:10.1029/2012GL051634, 2012.

Rignot, E., Velicogna, I., van den Broeke, M. R., Monaghan, A., and Lenaerts, J. T. M.: Acceleration of the contribution of the Greenland and Antarctic ice sheets to sea level rise, Geophys. Res. Lett., 38, L05503, doi:10.1029/2011GL046583, 2011.
Rignot, E., Fenty, I., Menemenlis, D., and Xu, Y.: Spreading of warm ocean waters around Greenland as a possible cause for glacier acceleration, Ann. Glaciol., 53, 257-266, doi:10.3189/2012AoG60A136, 2012.

Robinson, A., Calov, R., and Ganopolski, A.: Greenland ice sheet model parameters constrained using simulations of the Eemian Interglacial, Clim. Past, 7, 381-396, doi:10.5194/cp-7-381-2011, 2011.

Sabaka, T. J., Rowlands, D. D., Luthcke, S. B., and Boy, J.-P.: Improving global mass flux solutions from Gravity Recovery and Climate Experiment (GRACE) through forward modeling and continuous time correlation, J. Geophys. Res., 115, B11403, doi:10.1029/2010JB007533, 2010.

Schlegel, N. J., Larour, E., Seroussi, H., Morlighem, M., and Box, J. E.: Decadal-scale sensitivity of Northeast Greenland ice flow to errors in surface mass balance using ISSM, J. Geophys. Res.Earth Surf., 118, 667-680, 2013.

Schlegel, N.-J., Larour, E., Seroussi, H., Morlighem, M., and Box, J. E.: Ice discharge uncertainties in Northeast Greenland from boundary conditions and climate forcing of an ice flow model, J. Geophys. Res.-Earth Surf., 120, 29-54, doi:10.1002/2014JF003359, 2015.

Shepherd, A., Ivins, E. R., A, G., Barletta, V. R., Bentley, M. J., Bettadpur, S., Briggs, K. H., Bromwich, D. H., Forsberg, R., Galin, N., Horwath, M., Jacobs, S., Joughin, I., King, M. A., Lenaerts, J. T. M., Li, J., Ligtenberg, S. R. M., Luckman, A., Luthcke, S. B., McMillan, M., Meister, R., Milne, G., Mouginot, J., Muir, A., Nicolas, J. P., Paden, J., Payne, A. J., Pritchard, H., Rignot, E., Rott, H., Sorensen, L. S., Scambos, T. A., Scheuchl, B., Schrama, E. J. O., Smith, B., Sundal, A. V., van Angelen, J. H., van de Berg, W. J., van den Broeke, M. R., Vaughan, D. G., Velicogna, I., Wahr, J., Whitehouse, P. L., Wingham, D. J., Yi, D., Young, D., and Zwally, H. J.: A Reconciled Estimate of Ice-Sheet Mass Balance, Science, 338, 1183-1189, doi:10.1126/science.1228102, 2012.

Smith, L. C., Chu, V. W., Yang, K., Gleason, C. J., Pitcher, L. H., Rennermalm, A. K., Legleiter, C. J., Behar, A. E., Overstreet, B. T., Moustafa, S. E., Tedesco, M., Forster, R. R., LeWinter, A. L., Finnegan, D. C., Sheng, Y., and Balog, J.: Efficient meltwater drainage through supraglacial streams and rivers on the southwest Greenland ice sheet, P. Natl. Acad. Sci., 112, 1001-1006, doi:10.1073/pnas.1413024112, 2015.

Sundal, A. V., Shepherd, A., Nienow, P., Hanna, E., Palmer, S., and Huybrechts, P.: Melt-induced speed-up of Greenland ice sheet offset by efficient subglacial drainage, Nature, 469, 521-524, doi:10.1038/nature09740, 2011.

Tapley, B. D., Bettadpur, S., Ries, J. C., Thompson, P. F., and Watkins, M. M.: GRACE measurements of mass variability in the Earth system, Science, 305, 503-505, 2004.

Tedesco, M., Serreze, M., and Fettweis, X.: Diagnosing the extreme surface melt event over southwestern Greenland in 2007, The Cryosphere, 2, 159-166, doi:10.5194/tc-2-159-2008, 2008.

Tedesco, M., Fettweis, X., van den Broeke, M. R., van de Wal, R. S. W., Smeets, C. J. P. P., van de Berg, W. J., Serreze, M. C., and Box, J. E.: The role of albedo and accumulation in the 2010 melting record in Greenland, Environ. Res. Lett., 6, 014005, doi:10.1088/1748-9326/6/1/014005, 2011.

Tedesco, M., Fettweis, X., Mote, T., Wahr, J., Alexander, P., Box, J. E., and Wouters, B.: Evidence and analysis of 2012 Greenland 
records from spaceborne observations, a regional climate model and reanalysis data, The Cryosphere, 7, 615-630, doi:10.5194/tc7-615-2013, 2013a.

Tedesco, M., Willis, I. C., Hoffman, M. J., Banwell, A. F., Alexander, P., and Arnold, N. S.: Ice dynamic response to two modes of surface lake drainage on the Greenland ice sheet, Environ. Res. Lett., 8, 034007, doi:10.1088/1748-9326/8/3/034007, 2013b.

van den Broeke, M., Bamber, J., Ettema, J., Rignot, E., Schrama, E., van de Berg, W. J., van Meijgaard, E., Velicogna, I., and Wouters, B.: Partitioning Recent Greenland Mass Loss, Science, 326, 984 986, doi:10.1126/science.1178176, 2009.

van de Wal, R. S. W., Greuell, W., van den Broeke, M. Reijmer, C. H., and Oerlemans, J.: Surface mass-balance observations and automatic weather station data along a transect near Kangerlussuaq West Greenland, Ann. Glaciol., 52, 311-316, doi:10.3189/172756405781812529, 2005.
Velicogna, I. and Wahr, J.: Acceleration of Greenland ice mass loss in spring 2004, Nature, 443, 329-331, doi:10.1038/nature05168, 2006.

Vernon, C. L., Bamber, J. L., Box, J. E., van den Broeke, M. R., Fettweis, X., Hanna, E., and Huybrechts, P.: Surface mass balance model intercomparison for the Greenland ice sheet, The Cryosphere, 7, 599-614, doi:10.5194/tc-7-599-2013, 2013.

Zwally, H. J., Abdalati, W., Herring, T., Larson, K., Saba, J., and Steffen, K.: Surface melt-induced acceleration of Greenland IceSheet Flow, Science, 297, 218-222, 2002. 